\title{
The mechanism of Ccr4-Not recruitment to specific mRNAs involves sequence-selective tethering by RNA-binding proteins
}

\author{
Michael W Webster, James A W Stowell, Lori A Passmore* \\ MRC Laboratory of Molecular Biology, Cambridge CB2 0QH \\ *For correspondence: passmore@mrc-lmb.cam.ac.uk
}

\begin{abstract}
The Ccr4-Not complex removes mRNA poly(A) tails to regulate eukaryotic mRNA stability and translation. RNA-binding proteins contribute to specificity but this is not fully understood. Here, we reconstitute accelerated and selective deadenylation of RNAs containing AU-rich elements (AREs) and Pumilio-response elements (PREs). We find that the fission yeast homologues of Tristetraprolin/TTP and Pumilio/Puf (Zfs1 and Puf3) act as molecular tethers: They recruit Ccr4-Not via multiple regions within low-complexity sequences, and bind specific RNA sequences via RNA-binding domains. Using a two-color assay to simultaneously monitor poly(A) tail removal from different RNAs, we demonstrate that Puf3 can distinguish between RNAs of very similar sequence. This is primarily due to differences in the dissociation rate constants. As a result, motif quality is a major determinant of mRNA stability for Puf3 targets in vivo. Together, we provide new insight into the selective deadenylation of specific mRNAs by Ccr4-Not, and the prediction of targeted mRNAs.
\end{abstract}

\section{INTRODUCTION}

Shortening or removal of mRNA poly(A) tails (deadenylation) represses gene expression in eukaryotes. The Ccr4-Not complex is a conserved deadenylase that can initiate cytoplasmic mRNA decay, and reduce translation by releasing poly(A)binding protein (Pab1/PABPC1) (Parker, 2012; Tucker et al., 2001). Ccr4-Not contains seven core subunits, including two poly(A)-specific exonucleases, Ccr4/CNOT6/CNOT6L and Caf1/Pop2/CNOT7/CNOT8 (Wahle and Winkler, 2013). It can be specifically recruited to mRNAs by RNA-binding proteins and the RNAinduced silencing complex (RISC). Ccr4-Not recruitment can also be modulated by codon optimality and covalent modifications of the RNA sequence (Du et al., 2016; Eulalio et al., 2009; Wahle and Winkler, 2013; Webster et al., 2018). Diverse biological processes depend on deadenylation, including embryogenesis, germline maintenance, cell proliferation, and attenuation of the immune response (Carballo et al., 1998; Leppek et al., 2013; Subtelny et al., 2014; Yamaji et al., 2017).

RNA-binding proteins such as Pumilio/Puf and Tristetraprolin/TTP can recognize sequence motifs in mRNAs, and also bind Ccr4-Not to target those RNAs for deadenylation (Wahle and Winkler, 2013). The set of transcripts targeted for repression and decay by a given RNA-binding protein is therefore defined by the distribution of its binding motifs across the transcriptome, and often includes groups of mRNAs that encode functionally related proteins. This generates RNA regulatory networks, structured such that a single protein can regulate the expression of numerous genes (Joshi et al., 2011; Keene, 2007; Lapointe et al., 2017; Wilinski et al., 
2015). Targets of RNA-binding proteins often include factors that regulate gene expression themselves, thereby forming gene expression cascades (Barckmann and Simonelig, 2013; Lapointe et al., 2017; Shyu et al., 1991; Wells et al., 2012). Identification of the mRNAs within these networks allows a better understanding of gene expression and the roles of RNA-binding proteins that regulate them.

Recently, three sequence elements that strongly promote mRNA destabilization were identified in an unbiased screen in zebrafish embryogenesis: the Pumilio-response element (PRE), the AU-rich element (ARE) and the miR-430 seed sequence (Rabani et al., 2017). PRE- and ARE-mediated mRNA destabilization is conserved from yeast to human but the set of mRNAs that contain these motifs are different across species (Brooks and Blackshear, 2013; Wells et al., 2015; Wickens et al., 2002; Wilinski et al., 2017). Consequently, the biological processes regulated by orthologous RNA-binding proteins are diverse across organisms.

The PRE sequence motif is recognized by a conserved RNA-binding domain found within the Pumilio protein family. A direct interaction between the Pumilio RNA-binding domain and the CNOT7/Caf1 exonuclease has been reported (Van Etten et al., 2012), but it is unknown if this is the only site of interaction on Ccr4-Not. The PRE that interacts with human PUM1 and PUM2 (UGUANAUA) is found in mRNAs encoding proteins involved in signaling pathways and neuronal processes (Bohn et al., 2018). In Saccharomyces cerevisiae (Sc), there are six Pumilio proteins. Of these, $S c$ Puf3 is most closely related to homologs in higher eukaryotes (Wickens et al., 2002). The RNA motif recognized by $S c$ Puf3 resembles that of the human PUM proteins but, additionally, cytosine is preferred in the -1 and -2 positions (Gerber et al., 2004; Kershaw et al., 2015; Lapointe et al., 2015; Wickens et al., 2002; Zhu et al., 2009). The closest homolog to human PUM in Schizosaccharomyces pombe (Puf3) also contains residues that define this additional selectivity pocket, and is therefore predicted to bind sequences containing an upstream cytosine (Qiu et al., 2012).

S. cerevisiae Puf3 is a key regulator of mitochondrial function (Lee and Tu, 2015; Saint-Georges et al., 2008). Consistent with this, its mRNA targets encode proteins localized to the mitochondria and involved in the oxidative phosphorylation pathway (Gerber et al., 2004; Kershaw et al., 2015; Lapointe et al., 2015; 2018). Many transcripts proposed to be regulated by ScPuf3 do not, however, show a clear link to this role (Kershaw et al., 2015). It is therefore unclear whether the function of $S c$ Puf3 is limited to mitochondrial regulation. Puf3 homologs in other organisms (including $S$. pombe) do not necessarily regulate mitochondrial function (Hogan et al., 2015).

The nine-nucleotide ARE motif (UUAUUUAUU) was identified in unstable mRNAs encoding cytokines and lymphokines in human cells (Caput et al., 1986; Chen and Shyu, 1995). This sequence is recognized by tandem zinc finger (TZF) proteins including tristetraprolin (TTP). TTP attenuates immunological responses by binding directly to Ccr4-Not via the CNOT1 and CNOT9 subunits, targeting AREcontaining transcripts for degradation (Brooks and Blackshear, 2013; Bulbrook et al., 2018; Fabian et al., 2013). Phosphorylation of TTP occurs as part of the p38 MAPK pathway, and this disrupts Ccr4-Not recruitment (Marchese et al., 2010). The $S$. pombe Zfs1 protein is homologous to TTP, and recognizes the same RNA motif (Cuthbertson et al., 2008; Wells et al., 2015). An interaction between Zfs 1 and Ccr4Not has not been characterized in fission yeast and the Ccr4-Not-interacting amino acid sequences of TTP are not clearly conserved in Zfs 1 . 
Understanding the molecular basis of accelerated deadenylation has been limited by the lack of a biochemical system containing purified components that reconstitutes this process. Previous studies have shown that a purified domain of the budding yeast Pumilio protein Mpt5 stimulates the activity of immunoprecipitated Ccr4-Not (Goldstrohm et al., 2006), and that isolated Caf1 is stimulated by addition of purified BTG2 and PABPC1 (Stupfler et al., 2016). We recently purified the complete seven-subunit $S$. pombe Ccr4-Not complex after overexpression of the subunits in insect cells (Stowell et al., 2016). Biochemical assays revealed that this recombinant complex was substantially more active than the isolated nuclease enzymes (Stowell et al., 2016; Webster et al., 2018). Co-expression of the conserved subunits of Ccr4-Not with Mmil, an RNA-binding protein found in fission yeast, generated a complex that deadenylated Mmil-target RNAs more rapidly than non-target RNAs (Stowell et al., 2016).

Here, we reconstitute accelerated and selective deadenylation of PRE- and ARE-containing RNAs using recombinant $S$. pombe proteins. We find that Puf3 and Zfs1 act as molecular tethers capable of inducing accelerated and RNA-selective deadenylation by Ccr4-Not in vitro. Biochemical and biophysical analyses of Puf3 binding to RNA reveal a high degree of sequence selectivity. Correspondingly, in $S$. cerevisiae RNA motif quality is a critical determinant of the RNAs stably bound by Puf3 in vivo. Collectively, our findings show that a substantially improved understanding of RNA-binding protein regulatory networks can be obtained through detailed analysis of motif quality.

\section{RESULTS}

\section{Deadenylation is stimulated by Puf3 and Zfs1 in vitro}

To characterize substrate-selective deadenylation in the presence of RNAbinding proteins, we reconstituted this process using purified proteins. Full-length Zfs1 and Puf3 were expressed recombinantly as N-terminal maltose-binding protein (MBP) fusion proteins, and intact recombinant seven-subunit S. pombe Ccr4-Not was purified as described previously (Stowell et al., 2016). Pull-down assays revealed that Puf3 and Zfs1 interact with isolated Ccr4-Not (Figure 1-figure supplement 1A). Therefore, like metazoan homologs, S. pombe Puf3 and Zfs1 bind directly to Ccr4Not.

By using a short model RNA substrate, deadenylation can be visualized at single-nucleotide resolution, and can be accurately quantified (Webster et al., 2017). To investigate whether Puf3 and Zfs 1 stimulate the deadenylation activity of Ccr4Not in vitro, we designed model RNA substrates containing the sequence motif recognized by either Puf3 or Zfs1 (PRE UGUAAAUA, or ARE UUAUUUAUU respectively, Figure 1-figure supplement $1 \mathrm{~B})$. These motifs were embedded within a synthetic 23-nucleotide sequence, upstream of a 30-adenosine poly(A) tail. Electrophoretic mobility shift assays confirmed that Puf3 and Zfs1 bind stably to their respective target RNAs (Figure 1-figure supplement 1C). The 1:1 stoichiometric protein-RNA complexes formed under these conditions were used as substrates in assays measuring the deadenylation activity of Ccr4-Not.

Ccr4-Not removed the poly(A) tails of both Puf3 and Zfs1 substrate RNAs in vitro. Puf3 and Zfs1 each stimulated deadenylation of their target RNAs: In the 
absence of Puf3, complete removal of the poly(A) tail from PRE-containing RNA occurred in approximately 32 minutes, whereas in the presence of Puf3 the reaction was complete in less than 2 minutes (Figure 1A and Figure 1-figure supplement 1DE). Therefore, addition of Puf3 increased the rate of deadenylation more than 20-fold. Zfs 1 similarly increased the rate of deadenylation of its target RNA to less than 2 minutes (Figure 1B and Figure 1-figure supplement 1D-E). Thus, both Puf3 and Zfs1 have striking effects on the rate of deadenylation.

Non-adenosine residues upstream of the poly(A) tail were also rapidly removed by Ccr4-Not when Puf3 or Zfs1 were present. The exonucleases stop when they reach nucleotides that correspond to the binding site of the protein, suggesting that either the RNA-binding proteins cannot be released by Ccr4-Not, or that deadenylation becomes very slow after release of the RNA binding protein. This is consistent with a model in which the specificity of Ccr4-Not for adenosine is substantially less evident when it is tethered to the RNA substrate for a prolonged period of time (Finoux and Séraphin, 2006). In addition, the deadenylation reaction appeared to be more processive in the presence of Puf3 or Zfs1 because RNA lacking a poly(A) tail was visible when RNA with an intact tail was still present in the reaction (Figure 1-figure supplement $1 \mathrm{~F}$ ). This indicates that the RNA-binding protein increases the stability of the interaction of Ccr4-Not with the target RNA substrate during the course of the reaction.

\section{Ccr4-Not has an intrinsic RNA preference}

In the absence of additional protein, Ccr4-Not is approximately 3-fold more active on the ARE-containing substrate than on the PRE-containing substrate (Figure 1 and Figure 1-figure supplement 1E). It is generally believed that additional protein factors confer mRNA-selectivity to Ccr4-Not, but this finding indicates Ccr4-Not may possess a moderate degree of intrinsic mRNA selectivity. We previously observed that Ccr4-Not was less active on RNA substrates with secondary structure in the upstream 3'-UTR (Stowell et al., 2016). The free energies of the predicted most stable structures calculated with RNAfold software are $-1.2 \mathrm{kcal} / \mathrm{mol}$ (Puf3-target RNA) and $-0.2 \mathrm{kcal} / \mathrm{mol}$ (Zfs1-target RNA). Thus, neither of the substrates tested here is predicted to form stable RNA secondary structure. Our data suggest that the rate at which different mRNAs are deadenylated in vivo may be modulated by sequenceselectivity intrinsic to the Ccr4-Not complex.

\section{Puf3 and Zfs1 recruit Ccr4-Not via extended low-complexity sequences}

To dissect the mechanism of accelerated deadenylation, we made a series of Puf3 and Zfs1 mutations and truncations, and tested their abilities to stimulate deadenylation. First, we tested whether the RNA-binding domains alone (Puf3 ${ }^{\mathrm{PUM}}$ and $\mathrm{Zfs} 1^{\mathrm{TZF}}$, Figure 2-figure supplement $\left.1 \mathrm{~A}-\mathrm{B}\right)$ affected deadenylation. Addition of Puf3 ${ }^{\text {PUM }}$ caused a modest acceleration (complete deadenylation in $\sim 20$ min compared to $\sim 32 \mathrm{~min}$; Figure 2A and Figure 2-figure supplement 1C,D). This is consistent with a reported interaction between the Pumilio domain and the Caf1/CNOT7 subunit of Ccr4-Not, that tethers RNA directly to the nuclease subunit to accelerate deadenylation (Goldstrohm et al., 2006; Van Etten et al., 2012). Since stimulation by Puf3 $^{\text {PUM }}$ was much less than with full-length Puf3, regions outside the Pumilio domain likely play an important role in the recruitment of Ccr4-Not. Interestingly, $\mathrm{Zfs}^{\mathrm{TZF}}$ was inhibitory to deadenylation. This may be because this domain conceals 
sequence elements that confer the higher level of intrinsic activity on the AREcontaining RNA.

To confirm that RNA binding is essential to the function of Puf3 and Zfs1, we generated full-length proteins with mutations in the RNA-binding interface (Puf3 ${ }^{\text {Mut: }}$

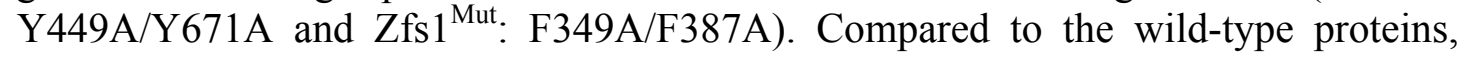
these mutants had a substantially reduced ability to bind their substrate RNAs, and to accelerate deadenylation (Figure 2A and Figure 2-figure supplement 1B-E). Together, these data show that the strong stimulatory effect of Puf3 and Zfs1 depends on RNA binding, but the RNA-binding domains alone are not sufficient.

In addition to a C-terminal RNA-binding domain, both Puf3 and Zfs1 contain an extended $\mathrm{N}$-terminal region of low amino acid sequence complexity that is predicted to be predominantly disordered (Figure 2B). We hypothesized that short sequence motifs within the low-complexity regions of Puf3 and Zfs1 interact with Ccr4-Not, as has been demonstrated for other interaction partners (Bhandari et al., 2014; Fabian et al., 2013; Raisch et al., 2016). Thus, we generated a series of Nterminal truncations and measured their effects on the deadenylation activity of Ccr4Not (Figure 2B and Figure 2-figure supplement $1 \mathrm{~F}-\mathrm{G}$ ). For both proteins, no single truncation accounted for the stimulatory effect on deadenylation. Instead, as the length of low-complexity sequence was reduced, the stimulatory effect on the deadenylation rate was also reduced. It is therefore likely that multiple sequence elements, distributed throughout the low-complexity regions, interact with Ccr4-Not.

\section{Non-enzymatic subunits of Ccr4-Not contribute to the interaction with Puf3 and Zfs1}

Two of the seven core subunits of Ccr4-Not are poly(A)-selective exonucleases, Caf1 and Ccr4. To determine whether Puf3 and Zfs 1 can stimulate deadenylation in the absence of the non-enzymatic subunits, we performed reactions with a purified dimeric subcomplex comprised of Cafl and Ccr4 (Stowell et al., 2016). Puf3 accelerated the rate of deadenylation by Caf1-Ccr4 substantially less than it accelerated intact Ccr4-Not (2-fold and $>20$-fold respectively, Figure $2 \mathrm{C}$ left compared to 1A). Fully-deadenylated and non-deadenylated RNA was observed simultaneously during both reactions, suggestive of a processive reaction. Furthermore, non-adenosine nucleotides were also readily removed by the Caf1-Ccr4 complex. This suggests that Puf3 interacts with Caf1-Ccr4, but association occurs more slowly when these subunits are not incorporated into the intact Ccr4-Not complex.

Zfs1 did not substantially affect the deadenylation activity of the Caf1-Ccr4 dimeric complex (Figure 2C, right). Thus, our data are consistent with Puf3 and Zfs1 recruiting the Ccr4-Not complex primarily through an interaction between their lowcomplexity regions and the non-enzymatic subunits of Ccr4-Not.

\section{Puf3 accelerates the release of Pab1}

Poly(A)-binding protein (Pab1) contributes to translation initiation, and its release from mRNAs can repress translation (Parker, 2012). Ccr4-Not efficiently releases Pab1 from the poly(A) tail through removal of the nucleotides to which it is bound (Webster et al., 2018). It is not known, however, how Pab1 influences 
accelerated deadenylation. We therefore examined deadenylation of Pab1-bound RNA in the presence of Puf3.

Electrophoretic mobility shift assays showed that stoichiometric amounts of Puf3 and Pab1 could be simultaneously loaded onto the RNA substrate (Figure 2figure supplement 2A). In deadenylation assays, the addition of Puf3 increased the rate at which the Pab1-bound poly(A) tail was removed by $\sim 8$-fold (Figure $2 \mathrm{D}$ and Figure 2-figure supplement 2B). Therefore, Puf3 can promote release of Pab1 by accelerating deadenylation by Ccr4-Not. Still, Pab1 slows the overall rate of Puf3accelerated deadenylation, suggesting that the rate of Pab1 release limits the very fast rate of deadenylation that occurs when Ccr4-Not is recruited by Puf3.

We previously reported that Caf1 and Ccr4 have similar activities within the purified Ccr4-Not complex (Stowell et al., 2016). More recently, we showed that the presence of Pab1 differentiates the activity of Ccr4 and Caf1: only Ccr4 removes adenosines bound by Pab1 (Webster et al., 2018). It is not known, however, whether Cafl and Ccr4 are differentially active when RNA-binding proteins recruit Ccr4-Not to specific mRNAs. We tested the contribution of Ccr4 and Caf1 to Puf3-accelerated deadenylation using purified Ccr4-Not variants with point mutants that abolish the catalytic activity of either nuclease.

Using our in vitro assays, Puf3 accelerated deadenylation by both Ccr4inactive and Caf1-inactive complexes (Figure 2-figure supplement 2C). This indicates that deadenylation in the presence of Puf3 is mediated by either nuclease. In the presence of Puf3 and Pab1, Ccr4-inactive Ccr4-Not did not proceed beyond $\sim 20$ adenosines (Figure 2-figure supplement 2C). This is similar to when Puf3 was not present (Webster et al., 2018). Thus, Pab1, and not Puf3, differentiates the two nucleases of Ccr4-Not.

\section{Puf3 and Zfs1 induce substrate-selective deadenylation by Ccr4-Not}

Having established that Puf3 and Zfs1 are capable of accelerating Ccr4-Not activity, we sought to test whether they are also sufficient for substrate-selectivity. We began by examining whether the presence of the target motif recognized by each protein was essential for accelerated deadenylation. The effect of Puf3 and Zfs 1 on its own target RNA was compared with its effect on a non-target RNA. For the latter, we used the RNA target of the other protein (Puf3 with Zfs1-target RNA, and Zfs1 with Puf3-target RNA). We were surprised to find that each protein stimulated deadenylation of an RNA that did not contain its target motif (Figure 3A). Quantification of deadenylation rates showed that on-target deadenylation was approximately 3-4 fold faster than off-target deadenylation, which was in turn 2-5 fold faster than when no additional protein was present (Figure 3-figure supplement 1A). Hence, the correct target RNA motif contributes to the ability of an RNAbinding protein to accelerate deadenylation in vitro, but is not absolutely required.

Since Puf3 with a mutated RNA-binding domain still stimulates deadenylation, allosteric activation of Ccr4-Not by the Puf3 low complexity region may contribute to this accelerated deadenylation of off-target RNAs (Figure 2-figure supplement 1D). However, mutant Zfs1 that does not bind RNA doesn't accelerate deadenylation. Thus, allosteric activation is not likely to be a general mechanism. Instead, we hypothesized that off-target stimulation of deadenylation in our in vitro experiments is due to off-target RNA binding. 
To determine the binding affinities of full-length Puf3 and Zfs1 for the RNA substrates, we performed fluorescence polarization RNA binding assays with RNAs containing the target motif of Puf3 or Zfs 1, as well as 30-mer polyadenosine (Figure 3B). Each RNA-binding protein bound to its respective target RNA sequence with high affinity $\left(K_{\mathrm{D}}=1-2 \mathrm{nM}\right)$. In contrast, Puf3 bound to the off-target ARE sequence with $K_{\mathrm{D}}$ of $120 \mathrm{nM}$, while Zfs1 bound the off-target PRE sequence with $K_{\mathrm{D}}$ of 850 nM. In both cases, poly(A) was bound with $\sim 100$-fold lower affinity than the target RNA. Hence, both Puf3 and Zfs 1 are selective in RNA binding, with $>100$-fold higher affinity for their target RNA than off-target RNAs. Still, Puf3 and Zfs1 bind off-target sequences with nanomolar affinities and this could account for their abilities to stimulate deadenylation of off-target RNAs.

We hypothesized that Puf3 and Zfs1 would select their targets from a mixture of target and non-target RNAs to promote targeted deadenylation. To test this, we developed a system to directly examine selective deadenylation by Ccr4-Not. Two polyadenylated RNA substrates labelled with different fluorophores were combined in stoichiometric quantities before the addition of Ccr4-Not and analysis of deadenylation activity. The same gel could therefore be used to monitor deadenylation of both the fluorescein-labelled Puf3-target substrate, and the Alexa647-labelled Zfs1target substrate, displayed in blue and red respectively (Figure 3C). In this two-color assay, the Zfs1-target RNA was deadenylated by Ccr4-Not 3-fold faster than the Puf3-target RNA in the absence of additional protein. This is consistent with intrinsic selectivity of Ccr4-Not that was observed when each RNA was examined in isolation (Figure 1).

We then performed a series of reactions using three different concentrations of Puf3 or Zfs1, and each RNA at $100 \mathrm{nM}$. With $50 \mathrm{nM}$ Puf3 or Zfs1, deadenylation was accelerated only on the target RNA (Figure 3D, top; blue for Puf3-target and red for Zfs1-target). A fraction of the target RNA was unaffected, consistent with incomplete occupancy of the RNA-binding protein on its target. With $250 \mathrm{nM}$ Puf3 or Zfs1, deadenylation of all target RNA was substantially increased while deadenylation of the non-target RNA was unchanged (Figure 3D, middle). Thus, Puf3 and Zfs1 promote selective, accelerated deadenylation. Selectivity was lost when an excess of the RNA-binding protein was added $(1000 \mathrm{nM})$ and all RNA was deadenylated rapidly (Figure 3D, bottom).

To examine RNA binding by Puf3 and Zfs1 under the same conditions, we performed electrophoretic mobility shift assays. Consistent with deadenylation assays, target RNA binding is complete and selective at $250 \mathrm{nM}$, but is non-selective at 1000 $\mathrm{nM}$ (Figure 3-figure supplement 1B). In conclusion, Puf3 and Zfs1 are sufficient for substrate-selective deadenylation by Ccr4-Not, within a given concentration window. At higher concentrations, they also bound to and accelerated deadenylation on RNAs that do not contain their target motif.

\section{Puf3 distinguishes between very similar motifs}

In the cell, RNAs with very similar sequences are present but RNA-binding proteins distinguish between these to act preferentially on specific targets. Yeasts possess multiple Pumilio proteins, and these recognize RNA motifs similar in sequence (Wickens et al., 2002). For example, an RNA target of $S$. cerevisiae $(S c)$ Puf3 differs from a target of $S c \mathrm{Puf5} / \mathrm{Mpt} 5$ in two nucleotide positions within a core 8nt motif (Goldstrohm et al., 2006) (Figure 4A, top). Given that Puf3 binds off-target 
RNAs at higher concentrations (Figure 3-figure supplement 1B), we investigated whether the fission yeast Puf3 distinguishes between the very similar motifs of ScPuf3 and $S c$ Puf5 in vitro.

We used fluorescence polarization experiments to examine RNA binding and found that $S$. pombe Puf3 ${ }^{\mathrm{PUM}}$ binds to both the ScPuf3 target and the ScPuf5 target with high affinity (Figure 4A, bottom). The affinity for the $S c \mathrm{Puf} 3$ motif is $\sim 2$-fold higher than for the ScPuf5 motif, but the binding affinity in both cases is in the picomolar range. Surprisingly, in deadenylation activity assays with $100 \mathrm{nM}$ Puf3, we found that the $S c$ Puf3 target was selectively deadenylated in preference to the ScPuf5 target (Figure 4B). Thus, Puf3 can distinguish between very similar RNAs and selectively target them for deadenylation by Ccr4-Not.

Selective deadenylation only occurred within a narrow range of Puf3 concentrations where the quantity of Puf3 protein is less than or equal to the quantity of ScPuf3-target RNA (Figure 4B, C). With less Puf3 (50 nM Puf3), not all ScPuf3target RNA was rapidly deadenylated. Conversely, when a molar excess of Puf3 was present (200 nM Puf3), both the ScPuf3- and ScPuf5-target RNAs were deadenylated rapidly. We performed RNA EMSAs and found that the ability of Puf3 to stimulate deadenylation correlated with RNA binding: binding to ScPuf5-target RNA occurred only when Puf3 protein was in molar excess to the $S c$ Puf3-target RNA (Figure 4D). Complete and selective binding by Puf3, and selective deadenylation by Ccr4-Not, therefore only occurs within a narrow window of Puf3 protein concentration.

We next examined whether Puf3 can distinguish between sequences that are even more similar. Within the 8-nucleotide motif recognized by $S c P u f 3$, the fifth position is the most variable, and A or $\mathrm{U}$ are thought to be tolerated (Kershaw et al., 2015). This is a property shared by the human homologs PUM1 and PUM2 (Galgano et al., 2008; Morris et al., 2008). In the previous experiments, the RNA motif contained A at position 5 (now called $S c$ Puf3-target(5A)). We tested whether there is a preference for $\mathrm{A}$ or $\mathrm{U}$ at position 5 using the two-color deadenylation assay and found that the $S c$ Puf3-target(5A) RNA was deadenylated in preference to ScPuf3target(5U) RNA (Figure 4E). Thus, Puf3 has a remarkable capacity to distinguish between sequences within the current definition of its target motif. The identity of the nucleotide in position 5 likely affects "motif quality", and Puf3 interacts with sequences of different quality in a priority-based manner.

\section{Kinetic basis of selective RNA binding by Puf3}

To gain insight into the selective RNA binding by Puf3 that allows it to distinguish between RNAs of very similar sequences, we analyzed the binding kinetics using SwitchSENSE (Knezevic et al., 2012). Switchable nanolevers were functionalized with RNAs containing each of the three RNA motifs tested in the deadenylation reactions: $S c$ Puf3-target(5A), $S c$ Puf3-target(5U), and $S c$ Puf5-target. We measured the rates of association $\left(k_{o n}\right)$ and dissociation $\left(k_{o f f}\right)$ of fission yeast Puf3 $^{\text {PUM }}$ binding to each of these, as well as to polyadenosine as a negative control.

Rates of association followed the same pattern of priority binding that we had identified by deadenylation assays and EMSA (Figure 5A): Association with the ScPuf3-target(5A) was $\sim 25 \%$ faster than with ScPuf3-target(5U) and $\sim$ three-fold faster than with the ScPuf5-target. Association with polyadenosine was even slower ( $\sim$ seven-fold). Thus, RNA sequence affects the rate of Puf3 association. Importantly, 
however, all sequences were bound rapidly: at a concentration of $20 \mathrm{nM}$, binding to all RNAs took place on the timescale of seconds (Figure 5A, right).

When we examined rates of dissociation, we found that Puf3 remained bound to the $S c$ Puf3-target with A at position 5 for twice as long as it remained bound to the RNA with $U$ at position 5, and $\sim$ three times as long as it was bound to the ScPuf5-target RNA (Figure 5B). Dissociation from polyadenosine occurred more than 100 -fold faster. Thus, rates of Puf3 dissociation also reflected the preference order that we had observed in deadenylation experiments. Combining our association and dissociation measurements, sequence-selective binding by Puf3 is expected to occur by the combination of rapid sampling of all RNAs with slower dissociation from sequences with higher motif quality.

\section{Motif quality affects $S c$ Puf3-bound transcripts in vivo}

The ability of Puf3 to discriminate between similar sequences is likely to play a role in defining the mRNAs within its regulatory network. To examine the contribution of RNA motif quality to Puf3 binding in vivo, we analyzed several published studies of $S$. cerevisiae Puf3. The mRNAs that contain Puf3 motifs are different between species, but we expected motif quality to be similarly important in all organisms (Hogan et al., 2015). Thus, we applied our in vitro findings using $S$. pombe proteins to a computational analysis of $S$. cerevisiae Puf3.

We compiled a list of 1331 putative ScPuf3 mRNA targets from three published sources. The first study of transcriptome-wide $S c$ Puf3 binding identified 220 targets by RNA immunoprecipitation followed by microarray analysis (RIP-chip) (Gerber et al., 2004). A more recent study using RNA immunoprecipitation followed by sequencing (RIP-seq) identified 1132 significantly enriched transcripts (Kershaw et al., 2015): the larger number of targets identified was attributed to the improved sensitivity of deep sequencing. A third study detected in vivo binding of ScPuf3 to 476 mRNAs using an RNA-tagging method (Lapointe et al., 2015). While there is substantial overlap between the binding targets from each list, 74\% of mRNAs were identified in only one of the three studies (Figure 6A). The set of mRNAs that are direct targets of $S c$ Puf3 regulation therefore remains unclear.

We began by computationally identifying the most enriched sequence motif in the complete set of 1331 mRNAs using MEME (Bailey et al., 2015). This had seven conserved nucleotides within an 8-nt motif (UGUANAUA), and was present in 627 mRNAs (41\% of total) (Figure 6B, top). The nucleotide at position 5 is variable, consistent with previous analyses of transcriptome-wide data (Gerber et al., 2004; Kershaw et al., 2015).

The best-characterized ScPuf3 binding site is within the COX17 mRNA (Olivas and Parker, 2000). This mRNA was also the most highly enriched following RNA-immunoprecipitation (Kershaw et al., 2015). Interestingly, it has sequence features outside the seven core nucleotides that contribute to the particularly high affinity binding of $S c$ Puf3: cytosine at position -2 and adenosine at position +5 (Zhu et al., 2009). Having identified that fission yeast Puf3 has the capacity to distinguish between similar sequences, we hypothesized that these additional sequence features might provide a better definition of $S c \mathrm{Puf} 3$ targets transcriptome-wide. Thus, we categorized target mRNAs by the presence of a ScPuf3-target motif as well as the nucleotide identity at positions -2 and +5 . We ranked these four groups by motif quality based on previously measured affinity values (Figure 6B and Supplementary 
File 1) (Zhu et al., 2009). Many of the predicted ScPuf3-target transcripts that do not fit into one of these four groups do not contain any of these sequences but have a motif in which one of the core seven nucleotides are altered (denoted here as " $\Delta$ core").

mRNAs that increase in steady-state abundance upon deletion of PUF3 represent high-confidence targets of $S c$ Puf3-mediated mRNA decay. 82 such mRNAs were identified previously (Kershaw et al., 2015), and we found that motif 1, 2 or 3 is present in 73 of these (89\%) (Figure 6C and Supplementary File 1). Furthermore, in 71 of the mRNAs that are increased in abundance upon PUF3 deletion, the motif is located within the 3' UTR. Hence, the quality and the location of ScPuf3 motifs both contribute to mRNA-destabilization.

We examined whether motif quality is correlated with the amount of ScPuf3 bound to mRNAs in vivo and found that transcripts that were most enriched in ScPuf3 immunoprecipitation experiments (Kershaw et al., 2015) had motif 1, 2 or 3 located in their 3'-UTR (Figure 6D and Supplementary File 1). In contrast, transcripts containing a group 4 motif, or a mismatch within the core seven nucleotides, generally had less ScPuf3 bound. Interestingly, mRNAs with high quality motifs located within the coding sequence were detected but were consistently bound by less $S c$ Puf3. Whether this reflects a lower occupancy of $S c P u f 3$, or a reduced stability of the interaction, is unknown. In summary, RNA sequence is an excellent predictor of $S c$ Puf3 binding in vivo.

\section{Motif quality defines a functionally homogeneous regulatory network}

In $S$. cerevisiae, Puf3 is a regulator of mitochondrial function (Lee and $\mathrm{Tu}$, 2015; Saint-Georges et al., 2008). Consistent with this, targets of ScPuf3 include mRNAs that encode proteins localized to the mitochondria and factors involved in the oxidative phosphorylation pathway (Gerber et al., 2004; Kershaw et al., 2015; Lapointe et al., 2015; 2018). Many transcripts identified as targets, however, show no clear link to this role (Kershaw et al., 2015). An important question therefore remains whether the role of ScPuf3 is limited to mitochondrial regulation.

We examined the link between the quality of ScPuf3-target motifs in mRNAs and the functions of the proteins they encode. A more detailed examination of gene function revealed that of the functionally annotated mRNAs containing motifs 1,2 or 3 in their 3' UTR, 245 of 278 (88\%) were related to mitochondrial biogenesis (Figure $6 \mathrm{E}$ and Supplementary File 2). This includes 74 of the 80 subunits of the mitochondrial ribosome (Bieri et al., 2018), but none of the cytoplasmic ribosome. Furthermore, the 14 mitochondrion-specific tRNA aminoacylation enzymes, but none of the 5 that are both mitochondrial and cytoplasmic, have a high quality ScPuf3 motif. Interestingly, transcripts encoding proteins that assemble the respiratory chain complexes, but not nuclear-encoded subunits of the complexes subunits themselves, are $S c$ Puf3 targets. Most components of the mitochondrial protein import complexes TIM22, TIM23 and TOM; mitochondrial chaperones; and membrane insertion factors are also targets. In contrast, mRNAs containing group 4 motif or $\Delta$ core were not generally related to mitochondrial function.

Compared to previous lists of ScPuf3 target candidates, analysis of motif quality yields a list of mRNA targets that is shorter and more functionally coherent (Figure 6-figure supplement 1A). To assess the limitations of predicting RNAbinding protein targets directly from mRNA sequence motif we examined ScPuf3 
binding and the sequence features of transcripts that had motif 1,2 or 3 in the $3^{\prime}$-UTR but encoded proteins not evidently related to mitochondrial biogenesis (33 in total), as well as mRNAs related to mitochondrial biogenesis but with motif 4 in the $3^{\prime}$-UTR (33 transcripts). These represent possible false-positives and false-negative predicted targets respectively. mRNAs with motif 1,2 or 3 that were not related to mitochondrial biogenesis had significantly less $S c$ Puf3 association than those that were related to mitochondria (Figure 6-figure supplement 1B). This suggests that despite the presence of a high-quality motif, $S c$ Puf3 binding is less enriched. Similarly, mRNAs with motif 4 that were related to mitochondrial biogenesis had higher levels of $S c P u f 3$, suggesting that despite sequences with lower motif quality, $S c$ Puf3 is selectively bound. Analysis of sequences surrounding the $S c$ Puf3-target motif revealed no consistent differences between functional groups (Figure 6-figure supplement 1C). Therefore, factors other than motif quality also influence ScPuf3 binding and this is correlated with encoded function.

\section{DISCUSSION}

The recruitment of enzymatic multi-protein complexes by RNA-binding adaptor proteins often facilitates post-transcriptional regulation of gene expression (Rissland, 2017). Here, we show by biochemical reconstitution that Puf3 and Zfs1 function as molecular tethers during deadenylation, bringing together specific mRNAs and exonucleases (Figure 7A). Interactions between the low-complexity regions of Puf3/Zfs1 and non-enzymatic subunits of Ccr4-Not are critical to this process. Sequence-selectivity of the RNA-binding proteins largely determines the selection of target RNAs for deadenylation. Moreover, the stability of the interaction between Puf3 and RNA is exquisitely sensitive to the RNA sequence. In vivo, this plays a major role in defining the functionally coherent RNA regulatory network of Puf3 in budding yeast, and likely in other organisms.

\section{Ccr4-Not recruitment by RNA-binding proteins}

RNA-binding proteins that interact with the mRNA decay machinery typically contain a canonical RNA-binding domain, and regions of low sequence complexity that are predicted to be structurally disordered (Jonas and Izaurralde, 2013). Short linear motifs within these regions can adopt secondary structure, and this may facilitate interaction with other proteins, including Ccr4-Not (Bhandari et al., 2014; Fabian et al., 2013; Raisch et al., 2016; Sgromo et al., 2017; Stowell et al., 2016). Recent work showed that Drosophila Nanos utilizes two short linear motifs to contact the NOT1 and NOT3 subunits of Ccr4-Not (Raisch et al., 2016). Likewise, the N- and C-terminal regions of human TTP interact with the CNOT1 and the CNOT9 subunits respectively (Bulbrook et al., 2018; Fabian et al., 2013; Lykke-Andersen and Wagner, 2005). We show that multiple regions within fission yeast Puf3 and Zfs1 contribute to Ccr4-Not recruitment, and these are distributed throughout the 300-400 amino acid region that is predicted to be predominantly disordered. Thus, the multi-partite mode of interaction for Puf3 and Zfs1 may be a general feature of RNA-binding proteins that interact with Ccr4-Not. The in vitro deadenylation assays described here represent a powerful tool for testing the importance of particular sequence regions in interaction partners and evaluating their redundancy.

The Pumilio family of RNA-binding proteins appeared to represent an exception to the pattern that Ccr4-Not recruitment occurs exclusively via short linear 
motifs within intrinsically disordered regions. The RNA-binding Pumilio domain of human PUM1 and S. cerevisiae Puf4 and Puf5 interacts directly with Caf1/CNOT8 (Goldstrohm et al., 2006). Consistent with this, in our study the S. pombe Puf3 PUM domain stimulated the rate of deadenylation by Ccr4-Not (Figure 2-figure supplement 1C), and full-length Puf3 stimulated deadenylation by a Caf1-Ccr4 subcomplex (Figure 2C). Importantly, however, both of these effects were weak relative to the stimulation of intact Ccr4-Not by full-length Puf3 (Figure 1A). Thus, the lowcomplexity region of $S$. pombe Puf3 and the non-enzymatic subunits of Ccr4-Not play important roles in the interaction. The Pumilio proteins are therefore likely similar to other Ccr4-Not interaction partners.

Intrinsically disordered regions are common sites of post-translational modification such as phosphorylation. TTP is a phosphorylation target in the p38 MAPK pathway, and this disrupts the recruitment of Ccr4-Not (Marchese et al., 2010). Similarly, phosphorylation occurs throughout the low-complexity region of $S$. cerevisiae Puf3, and this stops the rapid decay of transcripts to which it is bound (Lee and $\mathrm{Tu}, 2015)$. Given that the low-complexity region is involved in the recruitment of Ccr4-Not, it is likely that phosphorylation regulates this interaction. Rates of mRNA decay may be tuned by the extent of phosphorylation within the extended interface that contacts Ccr4-Not.

\section{A priority model of selective RNA binding}

The correct recognition of mRNA targets by RNA-binding proteins is critical for recruitment of effector complexes, such as Ccr4-Not. We found that Puf3 and Zfs1 stimulate deadenylation of off-target RNAs, but they can discriminate between mixtures of RNA substrates to select their target. Titration of Puf3 under conditions where two similar RNA sequences were present showed that binding of RNA occurs by a model of priority: Puf3 binds to an optimal target when it is available, but after saturation of all available sites, it will readily associate with a sub-optimal target (Figure 7B). This model of RNA target selection, where an RNA-binding protein has a distribution of affinities for different RNA sequences, challenges the model where there is a sharp distinction between affinities for specific and non-specific RNAs (Jankowsky and Harris, 2015). The relative abundance of RNA-binding proteins and RNA therefore determines occupancy, and is integral to the definition of the target motif.

We propose that tight control of RNA-binding protein abundance in the cell is essential for maintenance of a stable set of target mRNAs. Interestingly, the mRNA encoding Puf3 in S. cerevisiae is itself a target of Puf3 (Supplementary File 1). This predicts a potential feedback mechanism by which ScPuf3 protein abundance is autoregulated. Furthermore, the $S c$ Puf3-recognition motif within the $S c$ Puf3 mRNA is within group 4 (Figure 6B) and this is at the boundary that separates targets from nontargets. The ScPuf3 mRNA may only become destabilized when ScPuf3 protein abundance becomes high enough that it begins to destabilize mRNAs containing motifs of lower quality that are not related to mitochondrial biogenesis.

Increasing the level of human PUM1 by overexpression causes a number of mRNAs to be repressed, indicative of off-target RNA binding, and PUM1 availability may be regulated by a long noncoding RNA (Lee et al., 2016; Tichon et al., 2018). In mice, PUM1 is expressed constitutively, but heterozygotes that contain only a single gene copy display reduced PUM1 protein levels (Gennarino et al., 2015). This 
haploinsufficiency produces severely impaired neuronal function that is due, at least in part, to impaired destabilization of the ATAXIN1 mRNA. Thus, consistent with our model of RNA binding, the dosage of RNA-binding proteins is also important to maintain on-target mRNA expression.

\section{Identification of mRNA targets of RNA-binding proteins}

Even when the consensus motif recognized by an RNA-binding protein is known, it is often difficult to predict which transcripts are targeted by that protein in vivo: A high affinity interaction is not sufficient for the sequence to be a preferred target, as is exemplified by the tight binding of fission yeast Puf3 to the RNA motif recognized by $S c$ Puf5 (Figure 4A). Our kinetic analysis of Puf3 binding to RNA revealed a fast rate of association with RNA that does not contain the optimal sequence motif. We conclude that Puf3-RNA dissociation rates are likely major contributors to the rates of deadenylation.

In vivo, Puf3 likely samples numerous mRNAs before remaining stably associated with an mRNA containing an optimal sequence motif. An important consequence of this is that RNA-immunoprecipitation (and especially use of covalent crosslinking) will detect mRNAs that are not genuine targets. An indication of in vivo dissociation rates of $S c$ Puf3 were previously obtained using RNA tagging (Lapointe et al., 2015). In this method, an enzyme that adds uridines to the $3^{\prime}$ end of RNA is attached to the RNA-binding protein of interest. The length of the U-tail on an mRNA correlated with whether the mRNAs are regulated by $S c \mathrm{Puf} 3$ in the cell and is also expected to correlate with the duration the RNA-binding protein is associated with it (Lapointe et al., 2015). This study differentiated between Puf3 'sampling' of RNAs where the U-tails were short and the off-rate was too fast to allow regulation (deadenylation), and Puf3 'regulation' where the U-tails were longer, the off-rate is slower, and the interaction leads to a productive output (deadenylation). In addition to cellular concentration of RNA binding proteins and their targets, competition among RNA binding proteins with similar sequence preferences will also influence this kinetic model for productive interaction (Lapointe et al., 2017). Taken together, there is a striking convergence between the results of in vitro (this study) and in vivo (Lapointe et al., 2015) studies. Our analysis also correlates well with a more recent study that combined multiple methods to identify 91 Puf3 targets (Lapointe et al., 2018).

A major limitation in all experimental approaches is that the threshold separating genuine from non-genuine targets is difficult to define. Our analysis of the mRNA targets of $S$. cerevisiae Puf3 demonstrates, however, that accurate prediction may be possible from examination of the 3'-UTR sequence. If, as our data suggests, the function of $S$. cerevisiae Puf3 is limited to mitochondrial biogenesis, $\sim 88 \%$ of mRNAs with a high-quality motif are genuine targets. The workflow we have used should therefore be informative in defining the regulatory network of other RNAbinding proteins (Figure 7C).

How specific mRNAs can be rapidly and specifically targeted for degradation in response to cellular signals remains a major question in understanding eukaryotic gene expression. Our priority model for RNA binding to an adapter protein that acts as a tether to the deadenylation machinery provides new mechanistic insight and brings us closer to being able to predict RNA stability from sequence. 


\section{MATERIALS AND METHODS}

\section{Key Resources Table}

\begin{tabular}{|c|c|c|c|c|}
\hline $\begin{array}{l}\text { Reagent } \\
\text { type } \\
\text { (species) or } \\
\text { resource }\end{array}$ & Designation & $\begin{array}{l}\text { Source or } \\
\text { reference }\end{array}$ & Identifiers & Additional information \\
\hline $\begin{array}{l}\text { strain, strain } \\
\text { background } \\
\text { (Escherichia } \\
\text { coli) } \\
\end{array}$ & $\begin{array}{l}\text { E. coli BL21 } \\
\text { star (DE3) }\end{array}$ & $\begin{array}{l}\text { Thermo } \\
\text { Fisher } \\
\text { Scientific }\end{array}$ & C601003 & \\
\hline $\begin{array}{l}\text { strain, strain } \\
\text { background } \\
\text { (Escherichia } \\
\text { coli) }\end{array}$ & $\begin{array}{l}\text { E. coli DH5 } \\
\text { (DE3) }\end{array}$ & $\begin{array}{l}\text { Thermo } \\
\text { Fisher } \\
\text { Scientific }\end{array}$ & 18258012 & \\
\hline $\begin{array}{l}\text { cell line } \\
\text { (Spodoptera } \\
\text { frugiperda) }\end{array}$ & $S f 9$ & $\begin{array}{l}\text { Thermo } \\
\text { Fisher } \\
\text { Scientific }\end{array}$ & 11496015 & \\
\hline $\begin{array}{l}\text { peptide, } \\
\text { recombinant } \\
\text { protein }\end{array}$ & Ccr4-Not & $\begin{array}{l}\text { PMID: } \\
27851962 \\
\end{array}$ & & $\begin{array}{l}\text { Purified recombinant } \\
\text { protein expressed in Sf9 } \\
\text { cells following transfection } \\
\text { with LP_Ccr4Not }\end{array}$ \\
\hline $\begin{array}{l}\text { peptide, } \\
\text { recombinant } \\
\text { protein }\end{array}$ & $\begin{array}{l}\text { Ccr4-Not } \\
\text { (Ccr4- } \\
\text { inactive) }\end{array}$ & $\begin{array}{l}\text { PMID: } \\
27851962\end{array}$ & & $\begin{array}{l}\text { Purified recombinant } \\
\text { protein with Ccr4(E387) } \\
\text { expressed in Sf9 cells } \\
\text { following transfection with } \\
\text { LP_P22-60 }\end{array}$ \\
\hline $\begin{array}{l}\text { peptide, } \\
\text { recombinant } \\
\text { protein }\end{array}$ & $\begin{array}{l}\text { Ccr4- } \\
\text { Not(Caf1- } \\
\text { inactive) }\end{array}$ & $\begin{array}{l}\text { PMID: } \\
27851962\end{array}$ & & $\begin{array}{l}\text { Purified recombinant } \\
\text { protein with Caf1(D53A) } \\
\text { expressed in Sf9 cells } \\
\text { following transfection with } \\
\text { LP_P22-61 }\end{array}$ \\
\hline $\begin{array}{l}\text { peptide, } \\
\text { recombinant } \\
\text { protein }\end{array}$ & MBP-Puf3 & this paper & & $\begin{array}{l}\text { Purified recombinant } \\
\text { protein expressed in } E \text {. col } \\
\text { BL21 star (DE3) following } \\
\text { transformation with } \\
\text { LP_P22-27 }\end{array}$ \\
\hline $\begin{array}{l}\text { peptide, } \\
\text { recombinant } \\
\text { protein }\end{array}$ & $\begin{array}{l}\text { MBP- } \\
\text { Puf3( } \Delta 63)\end{array}$ & this paper & & $\begin{array}{l}\text { Purified recombinant } \\
\text { protein expressed in } E \text {. col } \\
\text { BL21 star (DE3) following } \\
\text { transformation with } \\
\text { LP_P22-28 }\end{array}$ \\
\hline $\begin{array}{l}\text { peptide, } \\
\text { recombinant } \\
\text { protein }\end{array}$ & $\begin{array}{l}\text { MBP- } \\
\text { Puf3( } \Delta 125)\end{array}$ & this paper & & $\begin{array}{l}\text { Purified recombinant } \\
\text { protein expressed in } E \text {.col } \\
\text { BL21 star (DE3) following } \\
\text { transformation with } \\
\text { LP_P22-29 }\end{array}$ \\
\hline $\begin{array}{l}\text { peptide, } \\
\text { recombinant } \\
\text { protein }\end{array}$ & $\begin{array}{l}\text { MBP- } \\
\text { Puf3( } \Delta 181)\end{array}$ & this paper & & $\begin{array}{l}\text { Purified recombinant } \\
\text { protein expressed in } E \text {. col } \\
\text { BL21 star (DE3) following } \\
\text { transformation with }\end{array}$ \\
\hline
\end{tabular}




\begin{tabular}{|c|c|c|c|}
\hline & & & LP_P22-30 \\
\hline $\begin{array}{l}\text { peptide, } \\
\text { recombinant } \\
\text { protein }\end{array}$ & $\begin{array}{l}\text { MBP- } \\
\operatorname{Puf3}(\Delta 240)\end{array}$ & this paper & $\begin{array}{l}\text { Purified recombinant } \\
\text { protein expressed in } E \text {. coli } \\
\text { BL21 star (DE3) following } \\
\text { transformation with } \\
\text { LP_P22-31 }\end{array}$ \\
\hline $\begin{array}{l}\text { peptide, } \\
\text { recombinant } \\
\text { protein }\end{array}$ & $\begin{array}{l}\text { MBP- } \\
\operatorname{Puf3}(\Delta 300)\end{array}$ & this paper & $\begin{array}{l}\text { Purified recombinant } \\
\text { protein expressed in E.coli } \\
\text { BL21 star (DE3) following } \\
\text { transformation with } \\
\text { LP_P22-32 }\end{array}$ \\
\hline $\begin{array}{l}\text { peptide, } \\
\text { recombinant } \\
\text { protein }\end{array}$ & $\begin{array}{l}\text { MBP- } \\
\operatorname{Puf3}(\Delta 378)\end{array}$ & this paper & $\begin{array}{l}\text { Purified recombinant } \\
\text { protein expressed in } E \text {. coli } \\
\text { BL21 star (DE3) following } \\
\text { transformation with } \\
\text { LP_P22-33 }\end{array}$ \\
\hline $\begin{array}{l}\text { peptide, } \\
\text { recombinant } \\
\text { protein }\end{array}$ & $\begin{array}{l}\text { MBP- } \\
\text { Puf3(Mut) }\end{array}$ & this paper & $\begin{array}{l}\text { Purified recombinant } \\
\text { protein expressed in E.coli } \\
\text { BL21 star (DE3) following } \\
\text { transformation with } \\
\text { LP_P22-34 }\end{array}$ \\
\hline $\begin{array}{l}\text { peptide, } \\
\text { recombinant } \\
\text { protein }\end{array}$ & Puf3(PUM) & this paper & $\begin{array}{l}\text { Purified recombinant } \\
\text { protein expressed in } E \text {.coli } \\
\text { BL21 star (DE3) following } \\
\text { transformation with } \\
\text { LP_P22-35 }\end{array}$ \\
\hline $\begin{array}{l}\text { peptide, } \\
\text { recombinant } \\
\text { protein }\end{array}$ & $\begin{array}{l}\text { MBP- } \\
\text { Zfs1(FL) }\end{array}$ & this paper & $\begin{array}{l}\text { Purified recombinant } \\
\text { protein expressed in E. coli } \\
\text { BL21 star (DE3) following } \\
\text { transformation with } \\
\text { LP_P22-36 }\end{array}$ \\
\hline $\begin{array}{l}\text { peptide, } \\
\text { recombinant } \\
\text { protein }\end{array}$ & $\begin{array}{l}\text { MBP- } \\
\text { Zfs } 1(\Delta 34)\end{array}$ & this paper & $\begin{array}{l}\text { Purified recombinant } \\
\text { protein expressed in E.coli } \\
\text { BL21 star (DE3) following } \\
\text { transformation with } \\
\text { LP_P22-37 }\end{array}$ \\
\hline $\begin{array}{l}\text { peptide, } \\
\text { recombinant } \\
\text { protein }\end{array}$ & $\begin{array}{l}\text { MBP- } \\
\mathrm{Zfs} 1(\Delta 71)\end{array}$ & this paper & $\begin{array}{l}\text { Purified recombinant } \\
\text { protein expressed in E.coli } \\
\text { BL21 star (DE3) following } \\
\text { transformation with } \\
\text { LP_P22-38 }\end{array}$ \\
\hline $\begin{array}{l}\text { peptide, } \\
\text { recombinant } \\
\text { protein }\end{array}$ & $\begin{array}{l}\text { MBP- } \\
\text { Zfs1 }(\Delta 182)\end{array}$ & this paper & $\begin{array}{l}\text { Purified recombinant } \\
\text { protein expressed in E. coli } \\
\text { BL21 star (DE3) following } \\
\text { transformation with } \\
\text { LP_P22-39 }\end{array}$ \\
\hline $\begin{array}{l}\text { peptide, } \\
\text { recombinant } \\
\text { protein }\end{array}$ & $\begin{array}{l}\text { MBP- } \\
\text { Zfs1( }(\Delta 248)\end{array}$ & this paper & $\begin{array}{l}\text { Purified recombinant } \\
\text { protein expressed in E.coli } \\
\text { BL21 star (DE3) following } \\
\text { transformation with } \\
\text { LP_P22-40 }\end{array}$ \\
\hline
\end{tabular}




\begin{tabular}{|c|c|c|c|c|}
\hline $\begin{array}{l}\text { peptide, } \\
\text { recombinant } \\
\text { protein }\end{array}$ & $\begin{array}{l}\text { MBP- } \\
\mathrm{Zfs} 1(\Delta 322)\end{array}$ & this paper & & $\begin{array}{l}\text { Purified recombinant } \\
\text { protein expressed in E. coli } \\
\text { BL21 star (DE3) following } \\
\text { transformation with } \\
\text { LP_P22-41 }\end{array}$ \\
\hline $\begin{array}{l}\text { peptide, } \\
\text { recombinant } \\
\text { protein }\end{array}$ & $\begin{array}{l}\text { MBP- } \\
\text { Zfs1(Mut) }\end{array}$ & this paper & & $\begin{array}{l}\text { Purified recombinant } \\
\text { protein expressed in E. coli } \\
\text { BL21 star (DE3) following } \\
\text { transformation with } \\
\text { LP_P22-42 }\end{array}$ \\
\hline $\begin{array}{l}\text { peptide, } \\
\text { recombinant } \\
\text { protein }\end{array}$ & Zfs1(TZF) & this paper & & $\begin{array}{l}\text { Purified recombinant } \\
\text { protein expressed in E. coli } \\
\text { BL21 star (DE3) following } \\
\text { transformation with } \\
\text { LP_P22-43 }\end{array}$ \\
\hline $\begin{array}{l}\text { peptide, } \\
\text { recombinant } \\
\text { protein }\end{array}$ & Pab1 & $\begin{array}{l}\text { PMID: } \\
29932902\end{array}$ & & \\
\hline $\begin{array}{l}\text { commercial } \\
\text { assay or kit }\end{array}$ & $\begin{array}{l}\text { Quikchange } \\
\text { Lightning } \\
\text { Multi Site- } \\
\text { Directed } \\
\text { Mutagenesis } \\
\text { Kit } \\
\end{array}$ & $\begin{array}{l}\text { Agilent } \\
\text { Technologies }\end{array}$ & 210513 & \\
\hline $\begin{array}{l}\text { commercial } \\
\text { assay or kit }\end{array}$ & $\begin{array}{l}\text { In-Fusion HD } \\
\text { Cloning Kit }\end{array}$ & Takara Bio & 121416 & \\
\hline $\begin{array}{l}\text { commercial } \\
\text { assay or kit }\end{array}$ & $\begin{array}{l}\text { Phusion High- } \\
\text { Fidelity DNA } \\
\text { Polymerase }\end{array}$ & $\begin{array}{l}\text { New } \\
\text { England } \\
\text { BioLabs } \\
\end{array}$ & M0530S & \\
\hline $\begin{array}{l}\text { recombinant } \\
\text { DNA } \\
\text { reagent }\end{array}$ & $\begin{array}{l}\text { MultiBac- } \\
\text { Ccr4Not }\end{array}$ & $\begin{array}{l}\text { PMID: } \\
27851962 \\
\end{array}$ & LP_Ccr4Not & $\begin{array}{l}\text { MultiBac expression vector } \\
\text { for } S \text {. pombe Ccr4-Not }\end{array}$ \\
\hline $\begin{array}{l}\text { recombinant } \\
\text { DNA } \\
\text { reagent }\end{array}$ & $\begin{array}{l}\text { MultiBac- } \\
\text { Ccr4Not(Ccr4 } \\
\text { E387A) }\end{array}$ & $\begin{array}{l}\text { PMID: } \\
27851962\end{array}$ & LP_P22-60 & $\begin{array}{l}\text { MultiBac expression vector } \\
\text { for } S \text {. pombe Ccr4-Not } \\
\text { (Ccr4 E387A) }\end{array}$ \\
\hline $\begin{array}{l}\text { recombinant } \\
\text { DNA } \\
\text { reagent }\end{array}$ & $\begin{array}{l}\text { MultiBac- } \\
\text { Ccr4Not(Caf1 } \\
\text { D53A) }\end{array}$ & $\begin{array}{l}\text { PMID: } \\
27851962\end{array}$ & LP_P22-61 & $\begin{array}{l}\text { MultiBac expression vector } \\
\text { for } S . \text { pombe Ccr4-Not } \\
\text { (Caf1 D53A) }\end{array}$ \\
\hline $\begin{array}{l}\text { recombinant } \\
\text { DNA } \\
\text { reagent }\end{array}$ & $\begin{array}{l}\text { pMAL-c2x- } \\
\text { Puf3(FL) }\end{array}$ & this paper & LP_P22-27 & $\begin{array}{l}\text { pMAL-c2x expression } \\
\text { vector for } S . \text { pombe } \\
\text { Puf3(FL) (res1-734) }\end{array}$ \\
\hline $\begin{array}{l}\text { recombinant } \\
\text { DNA } \\
\text { reagent }\end{array}$ & $\begin{array}{l}\text { pMAL-c2x- } \\
\operatorname{Puf3}(\Delta 63)\end{array}$ & this paper & LP_P22-28 & $\begin{array}{l}\text { pMAL-c2x expression } \\
\text { vector for } S . \text { pombe } \\
\text { Puf3( } \Delta 63)(\text { res63-734) }\end{array}$ \\
\hline $\begin{array}{l}\text { recombinant } \\
\text { DNA } \\
\text { reagent }\end{array}$ & $\begin{array}{l}\text { pMAL-c2x- } \\
\operatorname{Puf3}(\Delta 125)\end{array}$ & this paper & LP_P22-29 & $\begin{array}{l}\text { pMAL-c } 2 x \text { expression } \\
\text { vector for } S \text {. pombe } \\
\text { Puf3( } \Delta 125) \text { (res } 125-734)\end{array}$ \\
\hline $\begin{array}{l}\text { recombinant } \\
\text { DNA } \\
\text { reagent }\end{array}$ & $\begin{array}{l}\text { pMAL-c2x- } \\
\operatorname{Puf3}(\Delta 181)\end{array}$ & this paper & LP_P22-30 & $\begin{array}{l}\text { pMAL-c2x expression } \\
\text { vector for } S \text {. pombe } \\
\text { Puf3( } \Delta 181) \text { (res181-734) }\end{array}$ \\
\hline $\begin{array}{l}\text { recombinant } \\
\text { DNA }\end{array}$ & $\begin{array}{l}\text { pMAL-c2x- } \\
\operatorname{Puf3}(\Delta 240)\end{array}$ & this paper & LP_P22-31 & $\begin{array}{l}\text { pMAL-c2x expression } \\
\text { vector for } S \text {. pombe }\end{array}$ \\
\hline
\end{tabular}




\begin{tabular}{|c|c|c|c|c|}
\hline reagent & & & & $\operatorname{Puf3}(\Delta 240)($ res240-734) \\
\hline $\begin{array}{l}\text { recombinant } \\
\text { DNA } \\
\text { reagent }\end{array}$ & $\begin{array}{l}\text { pMAL-c2x- } \\
\operatorname{Puf} 3(\Delta 300)\end{array}$ & this paper & LP_P22-32 & $\begin{array}{l}\text { pMAL-c2x expression } \\
\text { vector for } S \text {. pombe } \\
\text { Puf3 }(\Delta 300)(\text { res300-734) }\end{array}$ \\
\hline $\begin{array}{l}\text { recombinant } \\
\text { DNA } \\
\text { reagent }\end{array}$ & $\begin{array}{l}\text { pMAL-c2x- } \\
\operatorname{Puf3}(\Delta 378)\end{array}$ & this paper & LP_P22-33 & $\begin{array}{l}\text { pMAL-c2x expression } \\
\text { vector for } S . \text { pombe } \\
\text { Puf3 }(\Delta 378)(\text { res378-734) }\end{array}$ \\
\hline $\begin{array}{l}\text { recombinant } \\
\text { DNA } \\
\text { reagent }\end{array}$ & $\begin{array}{l}\text { pMAL-c2x- } \\
\text { Puf3(Mut) }\end{array}$ & this paper & LP_P22-34 & $\begin{array}{l}\text { pMAL-c2x expression } \\
\text { vector for } S . \text { pombe } \\
\text { Puf3(Mut) (res1-734; } \\
\text { Y449A, Y671A) }\end{array}$ \\
\hline $\begin{array}{l}\text { recombinant } \\
\text { DNA } \\
\text { reagent }\end{array}$ & $\begin{array}{l}\text { pGEX6P-2- } \\
\text { Puf3(PUM) }\end{array}$ & this paper & LP_P22-35 & $\begin{array}{l}\text { pGEX6P-2 expression } \\
\text { vector for } S \text {. pombe } \\
\text { Puf3(PUM) (res378-714) }\end{array}$ \\
\hline $\begin{array}{l}\text { recombinant } \\
\text { DNA } \\
\text { reagent }\end{array}$ & $\begin{array}{l}\text { pMAL-c2x- } \\
\text { Zfs1(FL) }\end{array}$ & this paper & LP_P22-36 & $\begin{array}{l}\text { pMAL-c2x expression } \\
\text { vector for } S . \text { pombe } \\
\text { Zfs1(FL) (res1-404) }\end{array}$ \\
\hline $\begin{array}{l}\text { recombinant } \\
\text { DNA } \\
\text { reagent }\end{array}$ & $\begin{array}{l}\text { pMAL-c2x- } \\
\text { Zfs1 }(\Delta 34)\end{array}$ & this paper & LP_P22-37 & $\begin{array}{l}\text { pMAL-c2x expression } \\
\text { vector for } S . \text { pombe } \\
\text { Zfs1 }(\Delta 34)(\text { res34-404) }\end{array}$ \\
\hline $\begin{array}{l}\text { recombinant } \\
\text { DNA } \\
\text { reagent }\end{array}$ & $\begin{array}{l}\text { pMAL-c2x- } \\
\text { Zfs1 }(\Delta 71)\end{array}$ & this paper & LP_P22-38 & $\begin{array}{l}\text { pMAL-c } 2 \text { x expression } \\
\text { vector for } S . \text { pombe } \\
\text { Zfs } 1(\Delta 71)(\text { res } 71-404)\end{array}$ \\
\hline $\begin{array}{l}\text { recombinant } \\
\text { DNA } \\
\text { reagent }\end{array}$ & $\begin{array}{l}\text { pMAL-c2x- } \\
\text { Zfs1 }(\Delta 182)\end{array}$ & this paper & LP_P22-39 & $\begin{array}{l}\text { pMAL-c2x expression } \\
\text { vector for } S . \text { pombe } \\
\text { Zfs } 1(\Delta 182)(\text { res } 182-404)\end{array}$ \\
\hline $\begin{array}{l}\text { recombinant } \\
\text { DNA } \\
\text { reagent }\end{array}$ & $\begin{array}{l}\text { pMAL-c2x- } \\
\text { Zfs1 }(\Delta 248)\end{array}$ & this paper & LP_P22-40 & $\begin{array}{l}\text { pMAL-c } 2 x \text { expression } \\
\text { vector for } S . \text { pombe } \\
\text { Zfs } 1(\Delta 248)(\text { res } 248-404)\end{array}$ \\
\hline $\begin{array}{l}\text { recombinant } \\
\text { DNA } \\
\text { reagent }\end{array}$ & $\begin{array}{l}\text { pMAL-c2x- } \\
\text { Zfs } 1(\Delta 322)\end{array}$ & this paper & LP_P22-41 & $\begin{array}{l}\text { pMAL-c2x expression } \\
\text { vector for } S . \text { pombe } \\
\text { Zfs } 1(\Delta 322)(\text { res322-404) }\end{array}$ \\
\hline $\begin{array}{l}\text { recombinant } \\
\text { DNA } \\
\text { reagent }\end{array}$ & $\begin{array}{l}\text { pMAL-c2x- } \\
\text { Zfs1(Mut) }\end{array}$ & this paper & LP_P22-42 & $\begin{array}{l}\text { pMAL-c2x expression } \\
\text { vector for S. pombe } \\
\text { Zfs1(Mut) (res1-404; } \\
\text { F349A, F387A) }\end{array}$ \\
\hline $\begin{array}{l}\text { recombinant } \\
\text { DNA } \\
\text { reagent }\end{array}$ & $\begin{array}{l}\text { pGEX6P-2- } \\
\text { Zfs1(TZF) }\end{array}$ & this paper & LP_P22-43 & $\begin{array}{l}\text { pGEX6P-2 expression } \\
\text { vector for } S . \text { pombe } \\
\text { Zfs1(TZF) (res699-769) }\end{array}$ \\
\hline $\begin{array}{l}\text { recombinant } \\
\text { DNA } \\
\text { reagent }\end{array}$ & $\begin{array}{l}\text { pGEX6P-2- } \\
\text { Pab1 }\end{array}$ & $\begin{array}{l}\text { PMID: } \\
\text { 29932902 }\end{array}$ & LP_P22-11 & $\begin{array}{l}\text { pGEX6P-2 expression } \\
\text { vector for } S \text {. pombe Pab1 } \\
\text { (res80-653) }\end{array}$ \\
\hline $\begin{array}{l}\text { software, } \\
\text { algorithm }\end{array}$ & ImageJ & $\mathrm{NIH}$ & $\begin{array}{l}\text { https://image } \\
\text { j.nih.gov/ij/ }\end{array}$ & \\
\hline $\begin{array}{l}\text { software, } \\
\text { algorithm }\end{array}$ & $\begin{array}{l}\text { GraphPad } \\
\text { Prism } 6\end{array}$ & GraphPad & $\begin{array}{l}\text { https://www. } \\
\text { graphpad.co } \\
\text { m/scientific- } \\
\text { software/pris } \\
\text { m/ }\end{array}$ & \\
\hline $\begin{array}{l}\text { software, } \\
\text { algorithm }\end{array}$ & $\begin{array}{l}\text { switchANAL } \\
\text { YSIS }\end{array}$ & $\begin{array}{l}\text { Dynamic } \\
\text { Biosensors }\end{array}$ & $\begin{array}{l}\text { https://www. } \\
\text { dynamic- } \\
\text { biosensors.co }\end{array}$ & \\
\hline
\end{tabular}




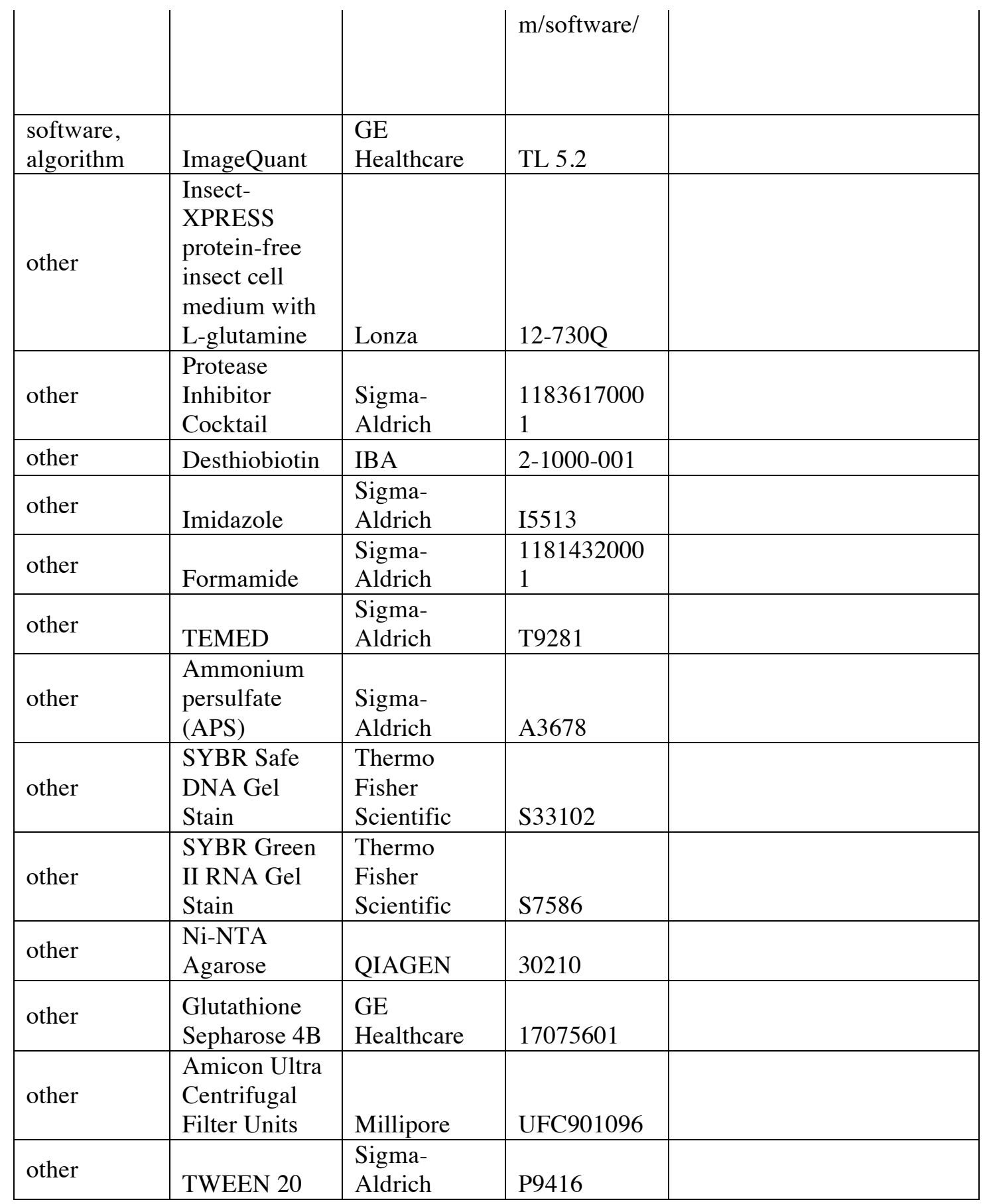




\section{Protein purification}

Intact Ccr4-Not complex was purified as described previously after overexpression of the seven core subunits of the Schizosaccharomyces pombe complex (Ccr4, Caf1, Not1, Not2, Not3, Not4/Mot2 and Rcd1/Caf40) in Sf9 cells (Stowell et al., 2016). The Caf1-Ccr4 heterodimeric complex was prepared as described previously from the $S f 9$ lysate used for Ccr4-Not expression (Webster et al., 2018). S. pombe Pab1 (amino acids 80-653) was prepared as described previously (Webster et al., 2018).

DNA sequences encoding full-length $S$. pombe Puf3 and Zfs1 were synthesized with codon optimization for E. coli (GenScript). Primers Puf3_Fwd and RBP_Rev were used to amplify the Puf3 sequence, and primers Zfss__Fwd and RBP_Rev were used to amplify the Zfs1 sequence (Supplementary File 3). DNA was inserted into pMAL-c2X expression vector using an In-Fusion HD Cloning Kit (Clontech). DNA encoding variants with $\mathrm{N}$-terminal truncations were amplified using primers Puf3_res $\{63,125,181,240,300,378\} \_$Fwd and RBP_Rev for Puf3 and Zfs1_res $\{34,71,182,248,322\} \_$Fwd and RBP_Rev for Zfs1. These were also inserted into pMAL-c2X. PCR-based site-directed mutagenesis was performed with a Quikchange Lightning Mutagenesis Kit (Agilent) to generate mutations in the Puf3 RNA-binding domain (Puf3 ${ }^{\text {Mut }}$ : Y449A/Y671A) and the Zfs1 RNA-binding domain $\left(Z f s 1^{\text {Mut }}\right.$ : F349A/F387A). Primers used to introduce mutations (Puf3_Quikchange and Zfs1_Quikchange) are listed in Supplementary File 3. Sequences of all expression vectors were confirmed by Sanger sequencing with primers pMAL_Seq_Fwd and pMAL_Seq_Rev.

Puf3 and Zfs1 were expressed as N-terminal MBP fusions in BL21 Star (DE3) E. coli (Thermo Fisher Scientific). Transformed cells were grown at $37{ }^{\circ} \mathrm{C}$ to an $\mathrm{A}_{600}$ $\mathrm{nm}$ of 0.6 before the temperature was reduced to $18{ }^{\circ} \mathrm{C}$ and protein expression induced by the addition of IPTG to $0.5 \mathrm{mM}$. Growth was continued for $18 \mathrm{~h}$ before cells were harvested by centrifugation and flash frozen for storage at $-80{ }^{\circ} \mathrm{C}$. Cells were defrosted and lysed by sonication in lysis buffer $(50 \mathrm{mM}$ Tris- $\mathrm{HCl} \mathrm{pH} 8,250 \mathrm{mM}$ $\mathrm{KCl}, 1 \mathrm{mM}$ TCEP) supplemented with protease inhibitor cocktail (Roche) and DNase I $(5 \mu \mathrm{g} / \mathrm{ml})($ Sigma $)$. The lysate was cleared by centrifugation at $40,000 \times \mathrm{g}$ for $30 \mathrm{~min}$ at $4{ }^{\circ} \mathrm{C}$. Supernatant was applied to amylose affinity resin $(1 \mathrm{ml}$ bed volume per 21 culture; New England Biolabs), and incubated with rotation for 1 hour at $4{ }^{\circ} \mathrm{C}$. Resin was separated from lysate with an Econo-Column (Bio-Rad) and washed three times with $50 \mathrm{ml}$ of RBP buffer (20 mM Tris- $\mathrm{HCl} \mathrm{pH} 8,50 \mathrm{mM} \mathrm{NaCl}, 0.1 \mathrm{mM}$ TCEP). Protein was eluted from the resin with RBP buffer supplemented with $50 \mathrm{mM}$ maltose. Sample was loaded onto a HiTrap Q HP 5-ml column (GE Healthcare), and the protein was eluted with a gradient of 20 column volumes into RBP buffer containing $1 \mathrm{M} \mathrm{NaCl}$. Protein in the elution peak was concentrated to $0.5 \mathrm{ml}$ with an Amicon Ultra concentrator ( $4 \mathrm{ml}, 50 \mathrm{kDa}$ MWCO, Millipore) by centrifugation at $3000 \times \mathrm{g}$ at $4{ }^{\circ} \mathrm{C}$. Sample was then applied to a Superdex $20010 / 300$ GL sizeexclusion column (GE Healthcare) equilibrated in RBP buffer. The column was run at $0.5 \mathrm{ml} / \mathrm{min}$ at $4{ }^{\circ} \mathrm{C}$. Full-length protein eluted at $10-13 \mathrm{ml}$, typically together with smaller protein species identified by tandem mass spectrometry to be truncated protein lacking C-terminal residues. The sample was applied to a HiTrap Heparin HP $5 \mathrm{ml}$ column (GE Healthcare), and the protein was eluted with a gradient of 20 column volumes into RBP buffer containing $1 \mathrm{M} \mathrm{NaCl}$. Full-length protein eluted at 
$\sim 250 \mathrm{mM} \mathrm{NaCl}$, while shorter fragments eluted at 100-200 mM NaCl. Peak fractions were concentrated with an Amicon Ultra $50 \mathrm{kDa}$ MWCO centrifugal concentrator (Millipore) and stored at $-80^{\circ} \mathrm{C}$.

The RNA-binding PUM domain of $S$. pombe Puf3 was defined as residues 378-714, while the RNA-binding TZF domain of $S$. pombe Zfs1 was defined as residues 699-769. DNA sequences encoding the RNA-binding domains of Puf3 $\left(\mathrm{Puf3}^{\mathrm{PUM}}\right.$ ) and $\mathrm{Zfs} 1$ (Zfs1 ${ }^{\mathrm{TZF}}$ ) were amplified from vectors encoding full-length proteins using primers Puf3_PUM_Fwd and Puf3_PUM_Rev or Zfs1_TZF_Fwd and Zfs1_TZF_Rev (Supplementary File 3). These were inserted into pG̈EX-6P-2 expression vector using an In-Fusion HD Cloning Kit (Clontech). Puf3 ${ }^{\text {PUM }}$ and Zfs $1^{\text {TZF }}$ were expressed as N-terminal GST fusions in BL21 Star (DE3) E. coli (Thermo Fisher Scientific). Expression and cell lysis were performed as described for full-length MBP-Puf3 and MBP-Zfs1. Clarified lysate was applied to glutathione sepharose 4B affinity resin ( $1 \mathrm{ml}$ bed volume per 21 culture; New England Biolabs), and incubated with rotation for 1 hour at $4{ }^{\circ} \mathrm{C}$. Resin was separated from lysate with an Econo-Column (Bio-Rad) and washed three times with $50 \mathrm{ml}$ of RBP buffer. Protein was eluted from the resin in $20 \mathrm{ml}$ of glutathione elution buffer $(20 \mathrm{mM}$ HEPES pH 7.4, $150 \mathrm{mM} \mathrm{NaCl}, 0.1 \mathrm{mM}$ TCEP, $50 \mathrm{mM}$ glutathione). The GST tag was cleaved by incubation with $1 \mathrm{mg}$ of $3 \mathrm{C}$ protease for $16 \mathrm{~h}$ at $4{ }^{\circ} \mathrm{C}$. Cleaved protein was buffer-exchanged into $20 \mathrm{mM}$ Bis-Tris $\mathrm{pH} 6.5,50 \mathrm{mM} \mathrm{NaCl}, 0.1 \mathrm{mM}$ TCEP with a HiPrep 26/10 desalting column (GE Healthcare). The sample was applied to a Mono S 5/50 GL cation-exchange column (GE Healthcare) and eluted over 20 column volumes into buffer supplemented to $1 \mathrm{M} \mathrm{NaCl}$. Pure protein eluted at $\sim 200 \mathrm{mM}$ $\mathrm{NaCl}$, and samples were pooled and stored at $-80{ }^{\circ} \mathrm{C}$.

\section{Deadenylation assays}

Deadenylation activity was measured as previously described (Webster et al., 2017). Puf3 and Zfs 1 were prepared in $20 \mathrm{mM}$ HEPES pH 7.4, $50 \mathrm{mM} \mathrm{NaCl}, 0.1 \mathrm{mM}$ TCEP and added to a final concentration of $250 \mathrm{nM}$ in the reaction, unless otherwise indicated. RBPs were incubated with RNA for 10 minutes at $22{ }^{\circ} \mathrm{C}$ prior to the addition of enzyme to allow protein-RNA binding to reach equilibrium. Puf3-targetA30 and Zfs1-target-A30 RNA were synthesized with a 5' 6-FAM fluorophore label (Integrated DNA Technologies). The RNAs were designed with a consensus Puf3 or Zfs 1 binding site ending 6 nucleotides upstream of a poly(A) tail, within a 23 nt nonpoly(A) sequence. $200 \mathrm{nM}$ RNA was used in each reaction. Ccr4-Not and Caf1-Ccr4 were prepared at $1 \mu \mathrm{M}(10 \times)$ in $20 \mathrm{mM}$ HEPES pH 7.4, $400 \mathrm{mM} \mathrm{NaCl}, 2 \mathrm{mM}$ $\mathrm{Mg}(\mathrm{OAc})_{2}, 0.1 \mathrm{mM}$ TCEP and added to a final concentration of $100 \mathrm{nM}$ in the reaction. Reactions were performed in $20 \mathrm{mM}$ PIPES pH 6.8, $10 \mathrm{mM} \mathrm{KCl}, 45 \mathrm{mM}$ $\mathrm{NaCl}, 2 \mathrm{mM} \mathrm{Mg}(\mathrm{OAc})_{2}, 0.1 \mathrm{mM}$ TCEP (includes components added with protein factors) at $22{ }^{\circ} \mathrm{C}$.

Reactions were stopped at the indicated time points by addition of $2 \times$ denaturing loading dye (95\% formamide, $10 \mathrm{mM}$ EDTA, $0.01 \% \mathrm{w} / \mathrm{v}$ bromophenol blue). Samples were applied to TBE (Tris-borate-EDTA), 20\% polyacrylamide gels containing $7 \mathrm{M}$ urea and run at $400 \mathrm{~V}$ in $1 \times$ TBE running buffer. Gels were scanned with a Typhoon FLA-7000 with excitation at $478 \mathrm{~nm}$. Densitometric analysis was performed with ImageJ as described previously (Schneider et al., 2012; Webster et al., 2017). Poly(A) tail lengths were calibrated using RNA markers with no tail and tails of known length. Intermediate tail lengths were calculated by counting bands on gels 
with single-nucleotide resolution as described previously (Webster et al., 2017). Deadenylation rates were calculated from a plot of the size of the most abundant RNA species versus time. Statistical significance was calculated by one-way ANOVA in GraphPad Prism.

For RNA competition experiments, Zfs1-target-A30 and ScPuf3(5U)-targetA30 RNAs were synthesized with a 5'-Alexa647 fluorophore label, and Puf5-targetA30 with a 5'-Cy3 fluorophore label (Integrated DNA Technologies). Reactions contained $100 \mathrm{nM}$ of each RNA, mixed prior to addition of protein factors. Gels were scanned twice with a Typhoon FLA-7000 with excitation at $478 \mathrm{~nm}$ (fluorescein detection) and either $633 \mathrm{~nm}$ (Alexa647 detection) or $573 \mathrm{~nm}$ (Cy3 detection). Images were superimposed with color overlay.

\section{Electrophoretic mobility shift assays}

Binding reactions $(10 \mu \mathrm{l})$ were prepared by adding protein at the indicated concentration to RNA (200 nM) in $20 \mathrm{mM}$ PIPES pH 6.8, $10 \mathrm{mM} \mathrm{KCl}, 90 \mathrm{mM} \mathrm{NaCl}$, $2 \mathrm{mM} \mathrm{Mg}(\mathrm{OAc})_{2}, 0.1 \mathrm{mM}$ TCEP. For RNA competition experiments, $100 \mathrm{nM}$ of each RNA was mixed prior to addition of protein. The sample was incubated for 15 minutes at $22{ }^{\circ} \mathrm{C}$ before the addition of $6 \times$ loading dye $(30 \%$ glycerol and $0.2 \% \mathrm{w} / \mathrm{v}$ orange G). Samples were loaded onto $6 \%$ TBE-polyacrylamide non-denaturing gels and electrophoresis was performed at $100 \mathrm{~V}$ in $1 \times \mathrm{TBE}$ running buffer. Gels were scanned with a Typhoon FLA-7000 with excitation at $478 \mathrm{~nm}$ (fluorescein detection) and $633 \mathrm{~nm}$ (Alexa647 detection).

\section{Fluorescence polarization assays}

A two-fold protein dilution series was prepared in $20 \mathrm{mM}$ HEPES pH 7.4, 150 $\mathrm{mM} \mathrm{NaCl}$. Proteins were incubated for 2 hours at $22{ }^{\circ} \mathrm{C}$ with $0.2 \mathrm{nM} \mathrm{5'} 6$-FAM RNA (synthesized by IDT). Fluorescence polarization was measured with a PHERAstar Plus microplate reader (BMG Labtech). Dissociation constants were estimated by non-linear regression in GraphPad Prism 6. Error bars indicate the standard deviation in three replicate measurements.

\section{SwitchSENSE kinetic analysis}

Kinetic measurements were performed using a DRX series instrument with a MPC-48-2-Y1 chip (Dynamic Biosensors). Hybrid oligonucleotides were synthesized (IDT) with the RNA of interest (Table 1) at the $5^{\prime}$ end followed by single-stranded DNA complementary in sequence to the fluorescently labelled oligonucleotide on the chip. Annealing was performed by flowing $500 \mathrm{nM}$ oligonucleotide over the chip for $4 \mathrm{~min}$ in a buffer of $20 \mathrm{mM}$ HEPES pH 7.4, $40 \mathrm{mM} \mathrm{NaCl}$ and $0.001 \%$ Tween-20.

Purified Puf3 $^{\text {PUM }}$ (residues 378-714) was applied to the chip in binding buffer (20 mM HEPES pH 7.4, $150 \mathrm{mM} \mathrm{NaCl}$ and $0.001 \%$ Tween-20) at $20{ }^{\circ} \mathrm{C}$ with a flow rate of $30 \mu \mathrm{l} / \mathrm{min}$. For association measurements, a series of protein concentrations was tested: 5, 10, 15, 20, 25, 30, 50, $70 \mathrm{nM}$ for ScPuf3- and ScPuf5-target RNA; 50, $100,150,200 \mathrm{nM}$ for poly(A). The dynamic response represents the change in nanolever switch speed on the timescale $0-4 \mu \mathrm{sec}$ as described previously (Langer et al., 2013). The observed association rate $\left(K_{\text {obs }}\right)$ was estimated by fit of an exponential curve to data points collected with a sampling rate of 1 second with GraphPad Prism 6. Error bars indicate the standard error in three replicate measurements. Association 
rate $\left(k_{o n}\right)$ was calculated by linear regression analysis of the protein concentration series.

For analysis of dissociation rate, $20 \mathrm{nM}$ Puf3 ${ }^{\text {PUM }}$ was loaded onto RNA as described above. Binding buffer was then flowed across the chip at $20{ }^{\circ} \mathrm{C}$ with a flow rate of $30 \mu \mathrm{l} / \mathrm{min}$. Data points from dissociation experiments with $S c$ Puf3-target and $S c$ Puf5-target RNAs were averaged in $10 \mathrm{sec}$ intervals to improve the signal-to-noise. Dissociation rates $\left(k_{o f f}\right)$ were estimated by fitting of an exponential function with GraphPad Prism 6.

\section{Bioinformatic analysis of $S c P u f 3$ mRNA targets}

Saccharomyces cerevisiae mRNAs that are candidates for Puf3 regulation were collated from published sources (Gerber et al., 2004; Kershaw et al., 2015; Lapointe et al., 2015). Proportional Venn diagram of gene overlap was generated with Biovenn (Hulsen et al., 2008) and redrawn for publication. 3'-UTR sequences were defined using poly(A) sites previously identified (Ozsolak et al., 2010). The most statistically enriched RNA motif from the combined set of 1331 mRNAs was identified with MEME (Bailey et al., 2015). Analysis of sequence context around the target motifs (10 nucleotides in each direction) was performed with WebLogo 3 (Crooks et al., 2004).

Motifs were identified in mRNA sequences with Geneious v 7.0.6 (Kearse et al., 2012) with the following general expressions: motif 1 (CNUGUAAAUA), motif 2 (CNUGUANAUA), motif 3 (UGUAAAUA) and motif 4 (UGUAAAUA). Sequences within motif category 1 are by definition within 2, 3 and 4. Once it was evident that mRNAs with motif 1 were significantly enriched in $S c P$ Puf3 relative to the remainder of mRNAs in categories 2, 3 and 4, they were assigned to a distinct category. No significant differences in ScPuf3 enrichment were detected between mRNAs with other permutations not presented $(-2$ : A, $\mathrm{U}$ or $\mathrm{G} ;-1$ any nucleotide; $+5 \mathrm{C}, \mathrm{G}$ or $\mathrm{U})$. For this reason, these sequences were treated as equivalent and the mRNAs containing them analyzed as a group. We do not exclude the possibility that differences in $S c$ Puf3 binding exist because statistically evaluation is limited to the number of endogenous genes containing each permutation. Motifs were assigned to the category $3^{\prime}$-UTR if at least part of the motif contained nucleotides $3^{\prime}$ of the coding sequence (including the stop codon). Statistical significance was evaluated with a MannWhitney rank comparison test in GraphPad Prism.

Gene ontology (GO) analysis was performed with PANTHER overrepresentation test using the dataset released on 2018-02-02 (Mi et al., 2017). Comprehensive GO term analysis of significant over-representation is available in Supplementary File 2. Detailed analysis of individual gene function was performed with the Saccharomyces Genome Database (http://yeastmine.yeastgenome.org) and the references contained therein.

\section{ACKNOWLEDGEMENTS}

We thank Terence Tang for comments on the manuscript; Jianguo Shi for assistance with baculovirus; and Stephen McLaughlin and Chris Johnson for assistance and advice with biophysical techniques. This work was supported by the European Research Council under the European Union's Seventh Framework Programme (FP7/ 2007-2013)/ERC Starting grant no. 261151 (to L.A.P); under the 
European Union's Horizon 2020 research and innovation programme (ERC Consolidator grant agreement No 725685) (to L.A.P); and Medical Research Council (MRC) grant MC_U105192715 (L.A.P).

\section{COMPETING INTERESTS}

The authors declare no competing interests.

\section{REFERENCES}

Bailey, T.L., Johnson, J., Grant, C.E., and Noble, W.S. (2015). The MEME Suite. Nucleic Acids Res. 43, W39-W49.

Barckmann, B., and Simonelig, M. (2013). Control of maternal mRNA stability in germ cells and early embryos. Biochim. Biophys. Acta 1829, 714-724.

Bhandari, D., Raisch, T., Weichenrieder, O., Jonas, S., and Izaurralde, E. (2014). Structural basis for the Nanos-mediated recruitment of the CCR4-NOT complex and translational repression. Genes Dev. $28,888-901$.

Bieri, P., Greber, B.J., and Ban, N. (2018). High-resolution structures of mitochondrial ribosomes and their functional implications. Curr. Opin. Struct. Biol. 49, 44-53.

Bohn, J.A., Van Etten, J.L., Schagat, T.L., Bowman, B.M., McEachin, R.C., Freddolino, P.L., and Goldstrohm, A.C. (2018). Identification of diverse target RNAs that are functionally regulated by human Pumilio proteins. Nucleic Acids Res. 46, 362-386.

Brooks, S.A., and Blackshear, P.J. (2013). Tristetraprolin (TTP): interactions with mRNA and proteins, and current thoughts on mechanisms of action. Biochim. Biophys. Acta 1829, 666-679.

Bulbrook, D., Brazier, H., Mahajan, P., Kliszczak, M., Fedorov, O., Marchese, F.P., Aubareda, A., Chalk, R., Picaud, S., Strain-Damerell, C., et al. (2018). Tryptophan-Mediated Interactions between Tristetraprolin and the CNOT9 Subunit Are Required for CCR4-NOT Deadenylase Complex Recruitment. J. Mol. Biol. 430, 722-736.

Caput, D., Beutler, B., Hartog, K., Thayer, R., Brown-Shimer, S., and Cerami, A. (1986). Identification of a common nucleotide sequence in the 3'-untranslated region of mRNA molecules specifying inflammatory mediators. Proc. Natl. Acad. Sci. U.S.a. 83, 1670-1674.

Carballo, E., Lai, W.S., and Blackshear, P.J. (1998). Feedback inhibition of macrophage tumor necrosis factor-alpha production by tristetraprolin. Science 281, 1001-1005.

Chen, C.Y., and Shyu, A.B. (1995). AU-rich elements: characterization and importance in mRNA degradation. Trends Biochem. Sci. 20, 465-470.

Crooks, G.E., Hon, G., Chandonia, J.-M., and Brenner, S.E. (2004). WebLogo: a sequence logo generator. Genome Res. 14, 1188-1190.

Cuthbertson, B.J., Liao, Y., Birnbaumer, L., and Blackshear, P.J. (2008). Characterization of zfs1 as an mRNA-binding and -destabilizing protein in Schizosaccharomyces pombe. J. Biol. Chem. 283, 25862594.

Du, H., Zhao, Y., He, J., Zhang, Y., Xi, H., Liu, M., Ma, J., and Wu, L. (2016). YTHDF2 destabilizes $\mathrm{m}(6) A$-containing RNA through direct recruitment of the CCR4-NOT deadenylase complex. Nat Commun 7, 12626.

Eulalio, A., Helms, S., Fritzsch, C., Fauser, M., and Izaurralde, E. (2009). A C-terminal silencing 
domain in GW182 is essential for miRNA function. RNA 15, 1067-1077.

Fabian, M.R., Frank, F., Rouya, C., Siddiqui, N., Lai, W.S., Karetnikov, A., Blackshear, P.J., Nagar, B., and Sonenberg, N. (2013). Structural basis for the recruitment of the human CCR4-NOT deadenylase complex by tristetraprolin. Nat. Struct. Mol. Biol. 20, 735-739.

Finoux, A.-L., and Séraphin, B. (2006). In vivo targeting of the yeast Pop2 deadenylase subunit to reporter transcripts induces their rapid degradation and generates new decay intermediates. J. Biol. Chem. 281, 25940-25947.

Galgano, A., Forrer, M., Jaskiewicz, L., Kanitz, A., Zavolan, M., and Gerber, A.P. (2008).

Comparative analysis of mRNA targets for human PUF-family proteins suggests extensive interaction with the miRNA regulatory system. PLoS ONE 3, e3164.

Gennarino, V.A., Singh, R.K., White, J.J., De Maio, A., Han, K., Kim, J.-Y., Jafar-Nejad, P., di Ronza, A., Kang, H., Sayegh, L.S., et al. (2015). Pumilio1 haploinsufficiency leads to SCA1-like neurodegeneration by increasing wild-type Ataxin1 levels. Cell 160, 1087-1098.

Gerber, A.P., Herschlag, D., and Brown, P.O. (2004). Extensive association of functionally and cytotopically related mRNAs with Puf family RNA-binding proteins in yeast. PLoS Biol. 2, E79.

Goldstrohm, A.C., Hook, B.A., Seay, D.J., and Wickens, M. (2006). PUF proteins bind Pop2p to regulate messenger RNAs. Nat. Struct. Mol. Biol. 13, 533-539.

Hogan, G.J., Brown, P.O., and Herschlag, D. (2015). Evolutionary Conservation and Diversification of Puf RNA Binding Proteins and Their mRNA Targets. PLoS Biol. 13, e1002307.

Hulsen, T., de Vlieg, J., and Alkema, W. (2008). BioVenn - a web application for the comparison and visualization of biological lists using area-proportional Venn diagrams. BMC Genomics 9, 488.

Jankowsky, E., and Harris, M.E. (2015). Specificity and nonspecificity in RNA-protein interactions. Nat. Rev. Mol. Cell Biol. 16, 533-544.

Jonas, S., and Izaurralde, E. (2013). The role of disordered protein regions in the assembly of decapping complexes and RNP granules. Genes Dev. 27, 2628-2641.

Joshi, A., Van de Peer, Y., and Michoel, T. (2011). Structural and functional organization of RNA regulons in the post-transcriptional regulatory network of yeast. Nucleic Acids Res. 39, 9108-9117.

Kearse, M., Moir, R., Wilson, A., Stones-Havas, S., Cheung, M., Sturrock, S., Buxton, S., Cooper, A., Markowitz, S., Duran, C., et al. (2012). Geneious Basic: an integrated and extendable desktop software platform for the organization and analysis of sequence data. Bioinformatics 28, 1647-1649.

Keene, J.D. (2007). RNA regulons: coordination of post-transcriptional events. Nat. Rev. Genet. 8, 533-543.

Kershaw, C.J., Costello, J.L., Talavera, D., Rowe, W., Castelli, L.M., Sims, P.F.G., Grant, C.M., Ashe, M.P., Hubbard, S.J., and Pavitt, G.D. (2015). Integrated multi-omics analyses reveal the pleiotropic nature of the control of gene expression by Puf3p. Sci Rep 5, 15518.

Knezevic, J., Langer, A., Hampel, P.A., Kaiser, W., Strasser, R., and Rant, U. (2012). Quantitation of affinity, avidity, and binding kinetics of protein analytes with a dynamically switchable biosurface. J. Am. Chem. Soc. 134, 15225-15228.

Langer, A., Hampel, P.A., Kaiser, W., Knezevic, J., Welte, T., Villa, V., Maruyama, M., Svejda, M., Jähner, S., Fischer, F., et al. (2013). Protein analysis by time-resolved measurements with an electroswitchable DNA chip. Nat Commun 4, 2099.

Lapointe, C.P., Preston, M.A., Wilinski, D., Saunders, H.A.J., Campbell, Z.T., and Wickens, M. 
(2017). Architecture and dynamics of overlapped RNA regulatory networks. RNA 23, 1636-1647.

Lapointe, C.P., Stefely, J.A., Jochem, A., Hutchins, P.D., Wilson, G.M., Kwiecien, N.W., Coon, J.J., Wickens, M., and Pagliarini, D.J. (2018). Multi-omics Reveal Specific Targets of the RNA-Binding Protein Puf3p and Its Orchestration of Mitochondrial Biogenesis. Cell Syst 6, 125-135.e126.

Lapointe, C.P., Wilinski, D., Saunders, H.A.J., and Wickens, M. (2015). Protein-RNA networks revealed through covalent RNA marks. Nat. Methods 12, 1163-1170.

Lee, C.-D., and Tu, B.P. (2015). Glucose-Regulated Phosphorylation of the PUF Protein Puf3 Regulates the Translational Fate of Its Bound mRNAs and Association with RNA Granules. Cell Rep 11, 1638-1650.

Lee, S., Kopp, F., Chang, T.-C., Sataluri, A., Chen, B., Sivakumar, S., Yu, H., Xie, Y., and Mendell, J.T. (2016). Noncoding RNA NORAD Regulates Genomic Stability by Sequestering PUMILIO Proteins. Cell 164, 69-80.

Leppek, K., Schott, J., Reitter, S., Poetz, F., Hammond, M.C., and Stoecklin, G. (2013). Roquin Promotes Constitutive mRNA Decay via a Conserved Class of Stem-Loop Recognition Motifs. Cell $153,869-881$.

Lykke-Andersen, J., and Wagner, E. (2005). Recruitment and activation of mRNA decay enzymes by two ARE-mediated decay activation domains in the proteins TTP and BRF-1. Genes Dev. 19, 351-361.

Marchese, F.P., Aubareda, A., Tudor, C., Saklatvala, J., Clark, A.R., and Dean, J.L.E. (2010). MAPKAP kinase 2 blocks tristetraprolin-directed mRNA decay by inhibiting CAF1 deadenylase recruitment. J. Biol. Chem. 285, 27590-27600.

Mi, H., Huang, X., Muruganujan, A., Tang, H., Mills, C., Kang, D., and Thomas, P.D. (2017). PANTHER version 11: expanded annotation data from Gene Ontology and Reactome pathways, and data analysis tool enhancements. Nucleic Acids Res. 45, D183-D189.

Morris, A.R., Mukherjee, N., and Keene, J.D. (2008). Ribonomic analysis of human Pum1 reveals cistrans conservation across species despite evolution of diverse mRNA target sets. Mol. Cell. Biol. 28, 4093-4103.

Olivas, W., and Parker, R. (2000). The Puf3 protein is a transcript-specific regulator of mRNA degradation in yeast. EMBO J. 19, 6602-6611.

Ozsolak, F., Kapranov, P., Foissac, S., Kim, S.W., Fishilevich, E., Monaghan, A.P., John, B., and Milos, P.M. (2010). Comprehensive polyadenylation site maps in yeast and human reveal pervasive alternative polyadenylation. Cell 143, 1018-1029.

Parker, R. (2012). RNA degradation in Saccharomyces cerevisae. Genetics 191, 671-702.

Qiu, C., Kershner, A., Wang, Y., Holley, C.P., Wilinski, D., Keles, S., Kimble, J., Wickens, M., and Hall, T.M.T. (2012). Divergence of Pumilio/fem-3 mRNA binding factor (PUF) protein specificity through variations in an RNA-binding pocket. J. Biol. Chem. 287, 6949-6957.

Rabani, M., Pieper, L., Chew, G.-L., and Schier, A.F. (2017). A Massively Parallel Reporter Assay of 3' UTR Sequences Identifies In Vivo Rules for mRNA Degradation. Mol. Cell 68, 1083-1094.e1085.

Raisch, T., Bhandari, D., Sabath, K., Helms, S., Valkov, E., Weichenrieder, O., and Izaurralde, E. (2016). Distinct modes of recruitment of the CCR4-NOT complex by Drosophila and vertebrate Nanos. EMBO J. 35, 974-990.

Rissland, O.S. (2017). The organization and regulation of mRNA-protein complexes. WIREs RNA 8 , e1369. 
Saint-Georges, Y., Garcia, M., Delaveau, T., Jourdren, L., Le Crom, S., Lemoine, S., Tanty, V., Devaux, F., and Jacq, C. (2008). Yeast mitochondrial biogenesis: a role for the PUF RNA-binding protein Puf3p in mRNA localization. PLoS ONE 3, e2293.

Schneider, C.A., Rasband, W.S., and Eliceiri, K.W. (2012). NIH Image to ImageJ: 25 years of image analysis. Nat. Methods 9, 671-675.

Sgromo, A., Raisch, T., Bawankar, P., Bhandari, D., Chen, Y., Kuzuoglu-Öztürk, D., Weichenrieder, O., and Izaurralde, E. (2017). A CAF40-binding motif facilitates recruitment of the CCR4-NOT complex to mRNAs targeted by Drosophila Roquin. Nat Commun 8, 14307.

Shyu, A.B., Belasco, J.G., and Greenberg, M.E. (1991). Two distinct destabilizing elements in the c-fos message trigger deadenylation as a first step in rapid mRNA decay. Genes Dev. 5, 221-231.

Stowell, J.A.W., Webster, M.W., Kögel, A., Wolf, J., Shelley, K.L., and Passmore, L.A. (2016). Reconstitution of targeted deadenylation by the Ccr4-Not complex and the YTH domain protein Mmi1. Cell Rep 17, 1978-1989.

Stupfler, B., Birck, C., Séraphin, B., and Mauxion, F. (2016). BTG2 bridges PABPC1 RNA-binding domains and CAF1 deadenylase to control cell proliferation. Nat Commun 7, 10811.

Subtelny, A.O., Eichhorn, S.W., Chen, G.R., Sive, H., and Bartel, D.P. (2014). Poly(A)-tail profiling reveals an embryonic switch in translational control. Nature 508, 66-71.

Tichon, A., Perry, R.B.-T., Stojic, L., and Ulitsky, I. (2018). SAM68 is required for regulation of Pumilio by the NORAD long noncoding RNA. Genes Dev. 32, 70-78.

Tucker, M., Valencia-Sanchez, M.A., Staples, R.R., Chen, J., Denis, C.L., and Parker, R. (2001). The transcription factor associated Ccr4 and Cafl proteins are components of the major cytoplasmic mRNA deadenylase in Saccharomyces cerevisiae. Cell 104, 377-386.

Van Etten, J., Schagat, T.L., Hrit, J., Weidmann, C.A., Brumbaugh, J., Coon, J.J., and Goldstrohm, A.C. (2012). Human Pumilio proteins recruit multiple deadenylases to efficiently repress messenger RNAs. J. Biol. Chem. 287, 36370-36383.

Wahle, E., and Winkler, G.S. (2013). RNA decay machines: Deadenylation by the Ccr4-Not and Pan2Pan3 complexes. Biochim. Biophys. Acta 1829, 561-570.

Webster, M.W., Chen, Y.-H., Stowell, J.A.W., Alhusaini, N., Sweet, T., Graveley, B.R., Coller, J., and Passmore, L.A. (2018). mRNA Deadenylation Is Coupled to Translation Rates by the Differential Activities of Ccr4-Not Nucleases. Mol. Cell 70, 1089-1100.e8.

Webster, M.W., Stowell, J.A.W., Tang, T.T.L., and Passmore, L.A. (2017). Analysis of mRNA deadenylation by multi-protein complexes. Methods 126, 95-104.

Wells, M.L., Hicks, S.N., Perera, L., and Blackshear, P.J. (2015). Functional equivalence of an evolutionarily conserved RNA binding module. J. Biol. Chem. 290, 24413-24423.

Wells, M.L., Huang, W., Li, L., Gerrish, K.E., Fargo, D.C., Ozsolak, F., and Blackshear, P.J. (2012). Posttranscriptional regulation of cell-cell interaction protein-encoding transcripts by Zfs $1 \mathrm{p}$ in Schizosaccharomyces pombe. Mol. Cell. Biol. 32, 4206-4214.

Wickens, M., Bernstein, D.S., Kimble, J., and Parker, R. (2002). A PUF family portrait: 3'UTR regulation as a way of life. Trends Genet. 18, 150-157.

Wilinski, D., Buter, N., Klocko, A.D., Lapointe, C.P., Selker, E.U., Gasch, A.P., and Wickens, M. (2017). Recurrent rewiring and emergence of RNA regulatory networks. Proc. Natl. Acad. Sci. U.S.A. 114, E2816-E2825. 
Wilinski, D., Qiu, C., Lapointe, C.P., Nevil, M., Campbell, Z.T., Tanaka Hall, T.M., and Wickens, M. (2015). RNA regulatory networks diversified through curvature of the PUF protein scaffold. Nat Commun 6,8213.

Yamaji, M., Jishage, M., Meyer, C., Suryawanshi, H., Der, E., Yamaji, M., Garzia, A., Morozov, P., Manickavel, S., McFarland, H.L., et al. (2017). DND1 maintains germline stem cells via recruitment of the CCR4-NOT complex to target mRNAs. Nature 543, 568-572.

Zhu, D., Stumpf, C.R., Krahn, J.M., Wickens, M., and Hall, T.M.T. (2009). A 5' cytosine binding pocket in Puf3p specifies regulation of mitochondrial mRNAs. Proc. Natl. Acad. Sci. U.S.A. 106, 20192-20197. 


\section{FIGURES}
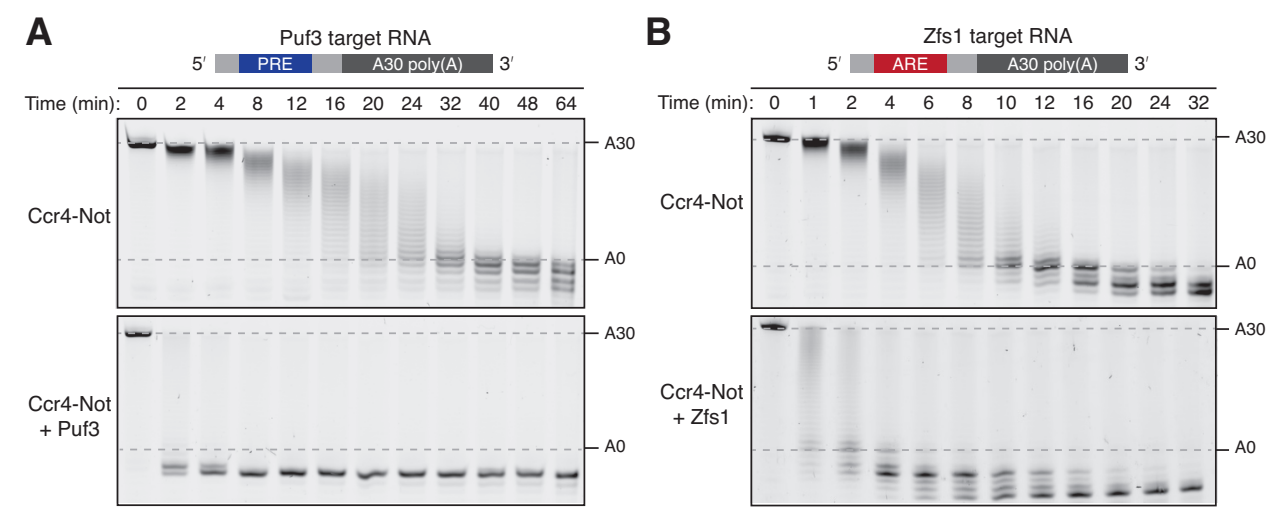

Figure 1. Puf3 and Zfs1 accelerate deadenylation by Ccr4-Not in vitro

Deadenylation by purified Ccr4-Not in the absence and presence of (A) Puf3 and (B) Zfs1. Synthetic RNA substrates were designed to contain a 30-adenosine poly(A) tail downstream of 23 non-poly(A) ribonucleotides including the recognition elements of Puf3 (PRE) or Zfs1 (ARE). RBP-RNA complexes were prepared at a 1:1 molar ratio before the addition of Ccr4-Not. Reactions were stopped at the indicated times and analyzed by denaturing PAGE. The sizes of the RNA substrate with and without the poly(A) tail are indicated by dashed lines. 


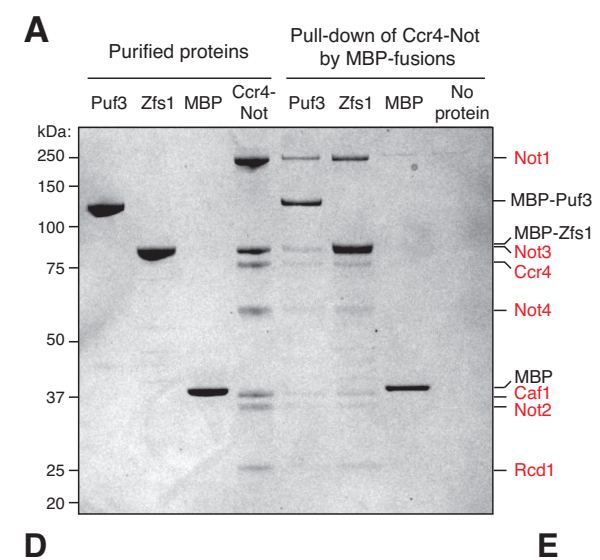

B $\quad$ C
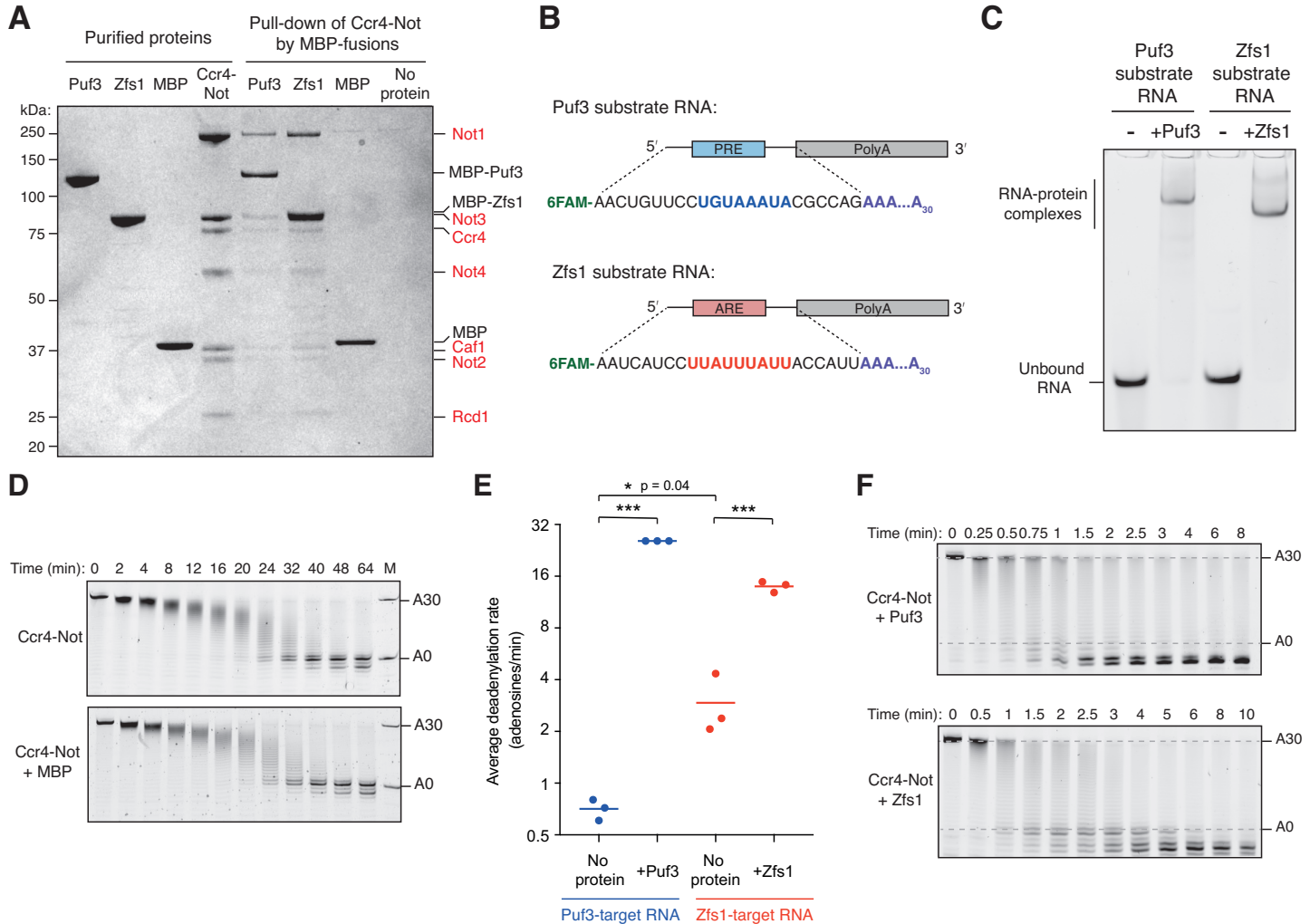

Figure 1-figure supplement 1. Acceleration of deadenylation by Puf3 and Zfs1

(A) Coomassie-stained SDS-PAGE of pull-down assay showing binding of Ccr4-Not (subunits labelled in red) to immobilized MBP-Puf3 and MBP-Zfs1. (B) Schematic diagram of RNA substrates showing 5' 6-FAM fluorescent label, position of Pumilioresponse element (PRE; blue), AU-rich element (ARE; red), and 30-adenosine poly(A) tail. (C) Electrophoretic mobility shift assay (EMSA) showing the proteinRNA complexes used as substrates for deadenylation assays. Puf3 or Zfs1 (250 nM) was incubated with labelled RNA $(200 \mathrm{nM})$ for 15 minutes at room temperature before resolving on a native polyacrylamide gel. (D) Control deadenylation assay with Puf3-target RNA showing that MBP alone does not have an effect on the deadenylation activity of Ccr4-Not. $M$ is marker for RNA with and without a poly $(\mathrm{A})_{30}$ tail. (E) Average rates of Ccr4-Not-mediated deadenylation in the presence of Puf3 or Zfs1. Reaction rates were calculated by densitometric analysis of denaturing polyacrylamide gels. The most abundant RNA size decreased linearly with time, and average reaction rates in number of adenosines removed/min were determined by linear regression on triplicate measurements. Each experiment is presented as a single data point, and the mean of each triplicate experiment is plotted as a horizontal line. Statistical significance was calculated by one-way ANOVA in GraphPad Prism. *, $\mathrm{p}=0.04 ; * * *, p=0.001$. (F) Fully-deadenylated and nondeadenylated RNA exist simultaneously in reactions with Ccr4-Not and Puf3 or Zfs1. Experiments were performed as in Figure 1 with shorter time increments. 
A

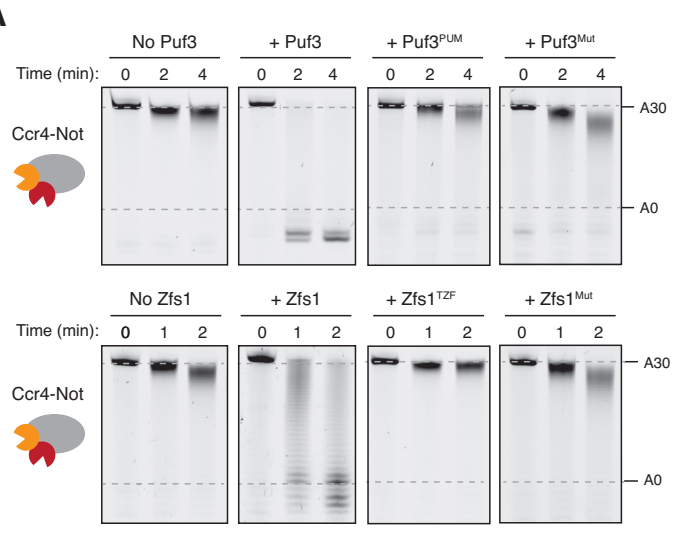

C
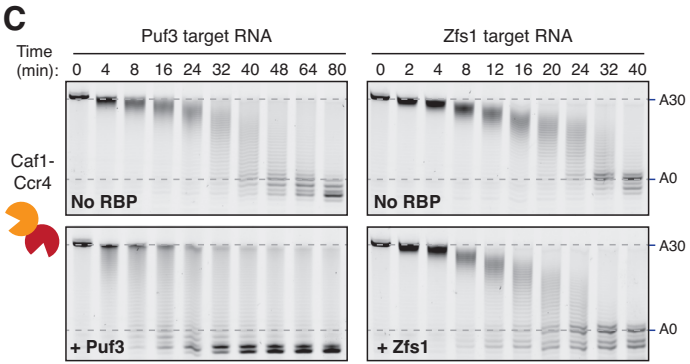

B
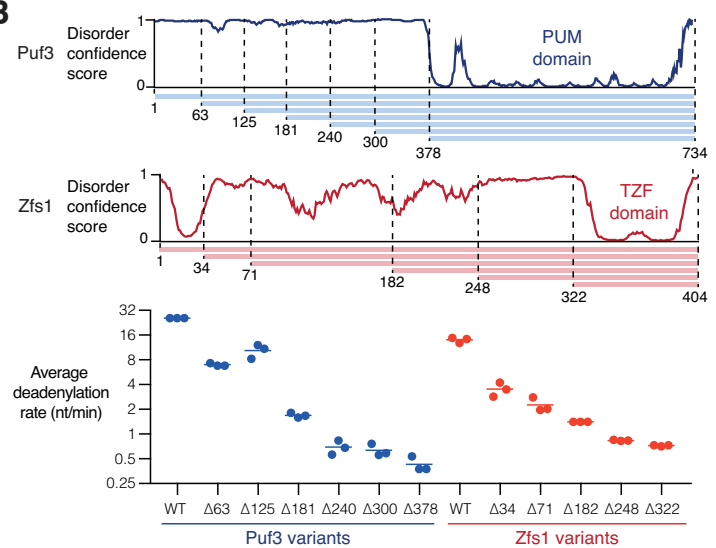

D

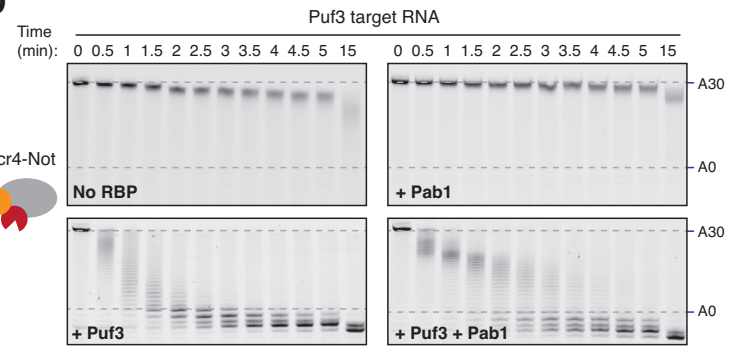

Figure 2. Recruitment of Ccr4-Not by Puf3 and Zfs1

Accelerated deadenylation by RNA binding proteins requires both a low-complexity region and RNA-binding activity. (A) Deadenylation by purified Ccr4-Not in the presence of the indicated RNA-binding protein variants was analyzed by denaturing PAGE. Puf3 ${ }^{\text {PUM }}$ and $\mathrm{Zfs} 1^{\text {TZF }}$ each comprise the RNA-binding domain alone; Puf3 ${ }^{\text {Mut }}$, $\mathrm{Zfs} 1^{\text {Mut }}$ are full-length proteins with point mutations that abolish RNA binding. Panels for no Puf3, no Zfs1, and wild-type proteins are reproduced from Figure 1. (B) The low-complexity domains of Puf3 and Zfs 1 contain multiple regions that contribute to deadenylation by Ccr4-Not. The upper panel shows diagrams of Puf3 and Zfs1 with regions of predicted disorder and truncated construct lengths. The bottom panel shows deadenylation by purified Ccr4-Not in the presence of the indicated protein variants, analyzed by denaturing PAGE. The most abundant RNA size decreased linearly with time, and average reaction rates in number of adenosines removed/min were determined by linear regression on triplicate measurements. Each experiment is plotted as a point and the mean is shown as a horizontal line. Statistical significance is shown in Figure 2-figure supplement 1G. (C) Deadenylation by the Caf1-Ccr4 nuclease subcomplex in the absence (No RBP) and presence of Puf3 and Zfs1. (D) Puf3-stimulated deadenylation by Ccr4-Not in the absence or presence of Pab1 $1: 1$ molar ratio to RNA). 
A

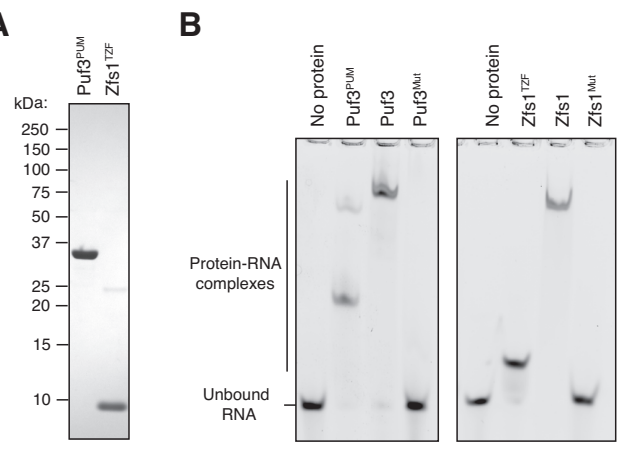

D

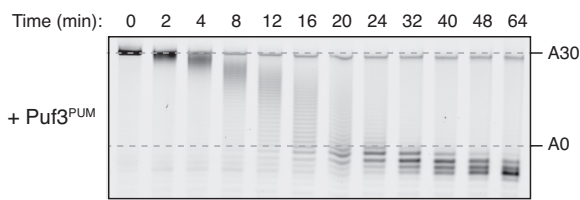

Time (min): $\quad \begin{array}{llllllllllll}0 & 1 & 2 & 4 & 6 & 8 & 10 & 12 & 16 & 20 & 24 & 32\end{array}$

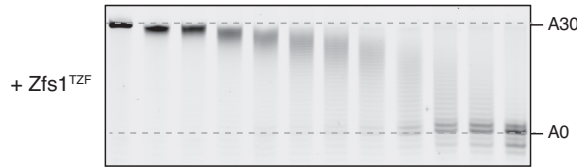

$\mathbf{F}$

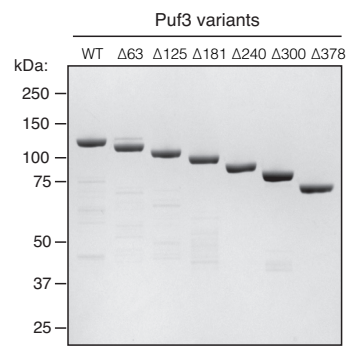

C

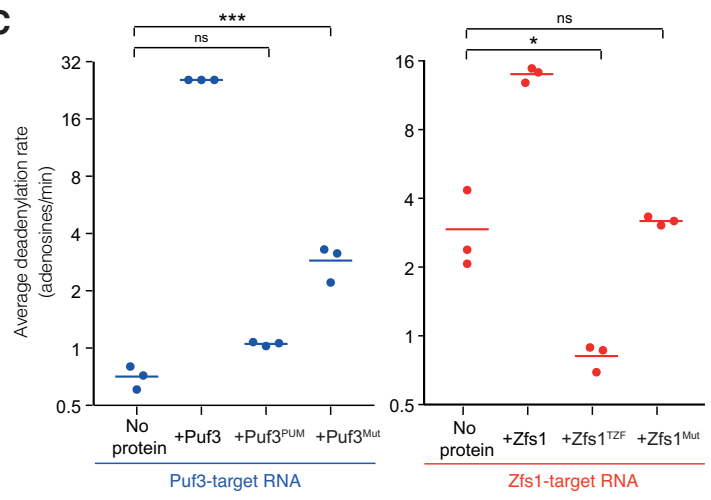

$\mathbf{E}$

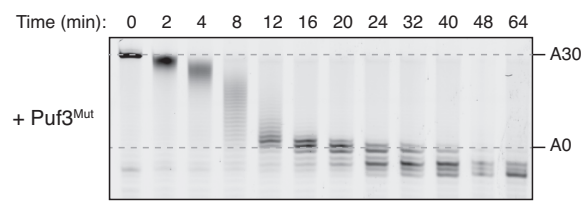

Time (min): $\begin{array}{lllllllllllll}0 & 1 & 2 & 4 & 6 & 8 & 10 & 12 & 16 & 20 & 24 & 32\end{array}$

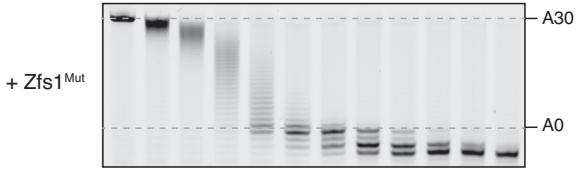

G

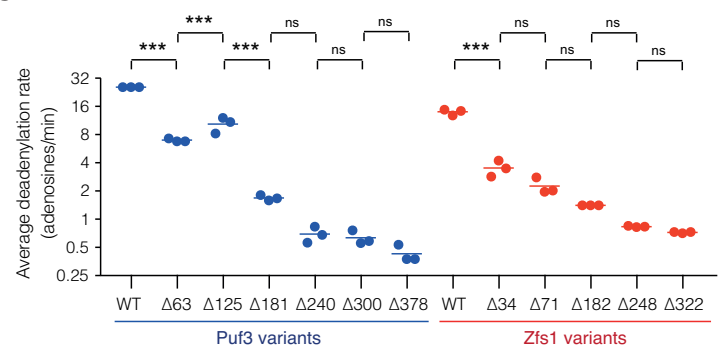

Figure 2-figure supplement 1. Characterization of Puf3 and Zfs1 domains required for accelerated deadenylation

(A) Coomassie-stained SDS-PAGE of purified RNA-binding domains: Puf3 residues 378-714 (Puf3 ${ }^{\mathrm{PUM}}$ ) and Zfs1 residues 322-392 (Zfs1 $\left.{ }^{\mathrm{TZF}}\right)$. (B) Electrophoretic mobility shift assay (EMSA) showing binding of the indicated RNA-binding proteins to poly(A)-containing RNAs used as substrates in deadenylation assays. (C) Average rates of Ccr4-Not-mediated deadenylation in the presence of the indicated Puf3 or Zfs 1 variants. Reaction rates were calculated by densitometric analysis of denaturing polyacrylamide gels. The most abundant RNA size decreased linearly with time, and average reaction rates in number of adenosines removed/min were determined by linear regression on triplicate measurements. Each experiment is presented as a single data point, with the mean $(n=3)$ shown as a horizontal line. Statistical significance was calculated by one-way ANOVA in GraphPad Prism. *, $\mathrm{p}=0.05$; ***, $\mathrm{p}=0.001$, n.s., not significant. (D, E) Full deadenylation reactions performed in the presence of the indicated Puf3 or Zfs1 variants as in Figure 2A. (F) Coomassie-stained SDSPAGE of purified Puf3 and Zfs1 N-terminal truncation variants. (G) Average rates of Ccr4-Not-mediated deadenylation in the presence of the indicated Puf3 or Zfs1 variants. The $\mathrm{p}$-values are as in panel $(\mathrm{C})$. 


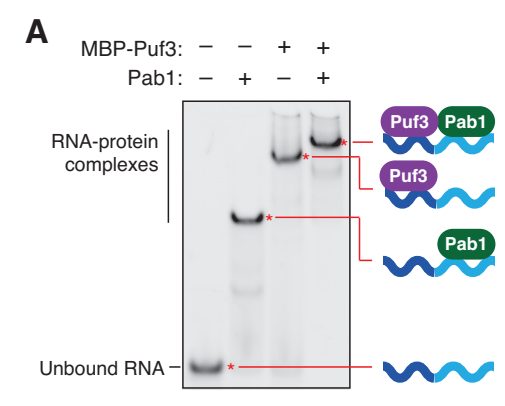

B

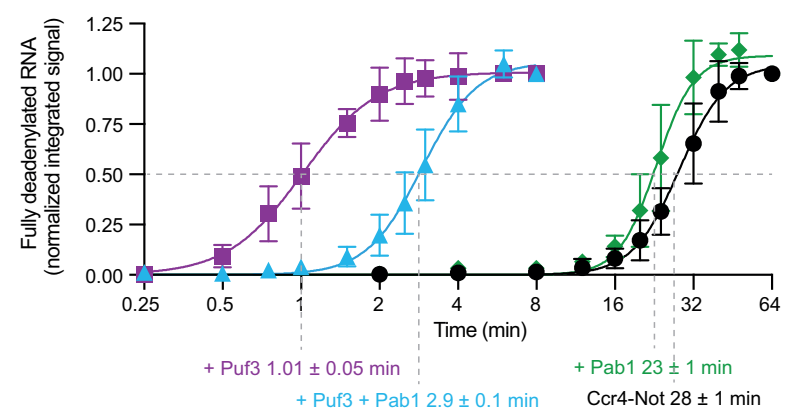

C
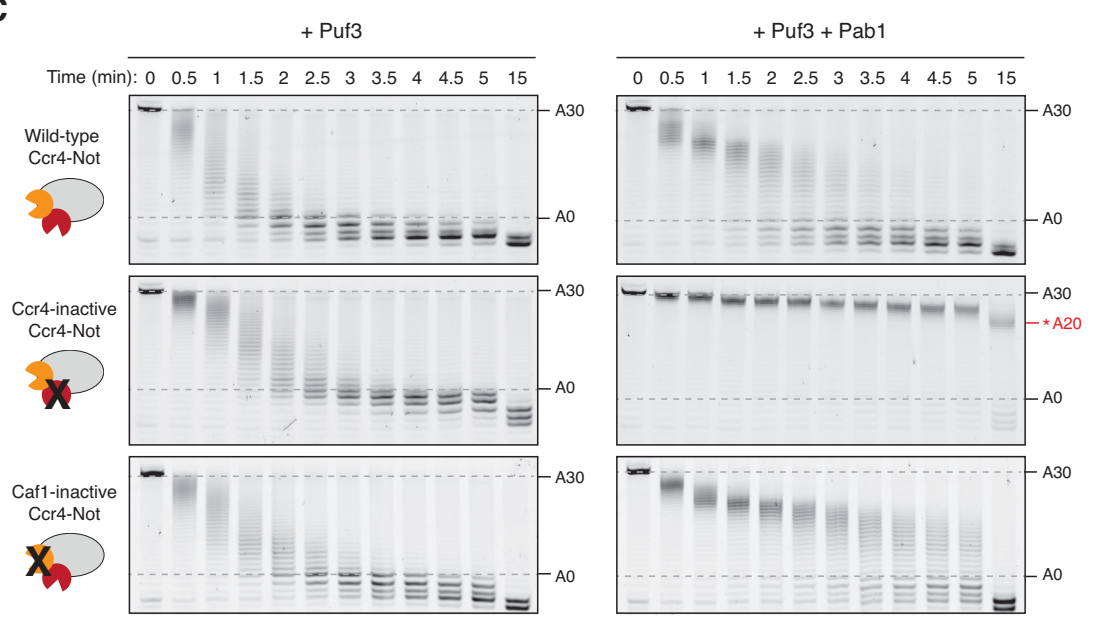

Figure 2-figure supplement 2. Puf3 accelerates deadenylation in the presence of Pab1

(A) Electrophoretic mobility shift assay showing the binding of MBP-Puf3 and Pab1 to the deadenylation substrate containing a Puf3 motif upstream of a 30-adenosine poly(A) tail. (B) Puf3 accelerates release of Pab1 during deadenylation by Ccr4-Not. Densitometric analysis of previously published data (Webster et al., 2018) and the reactions shown in Figure 2D to calculate the amount of fully deadenylated RNA. A quadratic fit of the data was used to determine the time taken for half of the RNA to be completely deadenylated. Reactions were performed in triplicate and the standard error is given. (C) Deadenylation by Ccr4-Not and variants with mutations in the active site of either Ccr4 (Ccr4-inactive) or Caf1 (Cafl-inactive) with Pab1 and Puf3. Reactions with wild-type Ccr4-Not are reproduced from Figure 2D. In the presence of Pab1, Ccr4-inactive Ccr4-Not stalls when $\sim 20$ As remain, as indicated. 
A

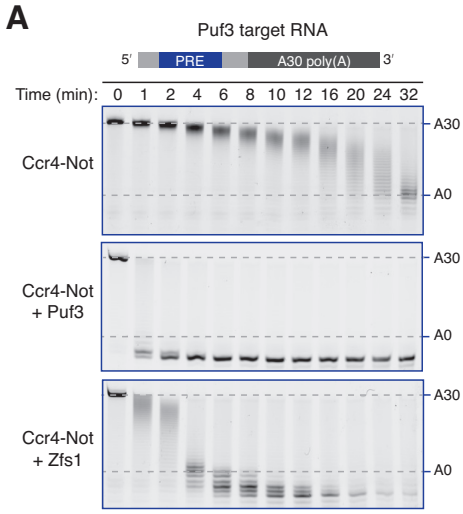

C
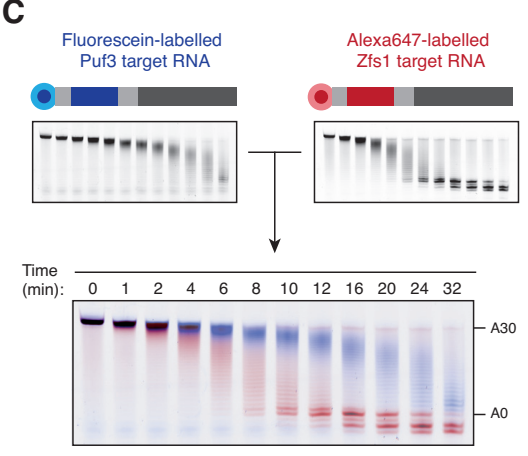

Zfs1 target RNA

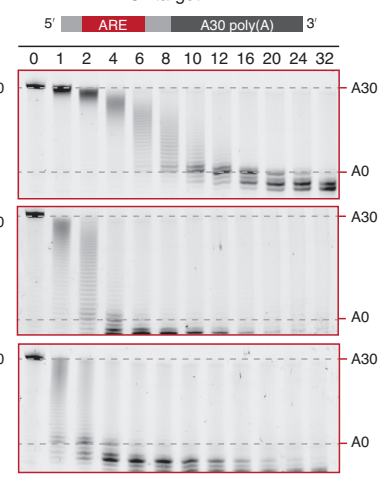

D

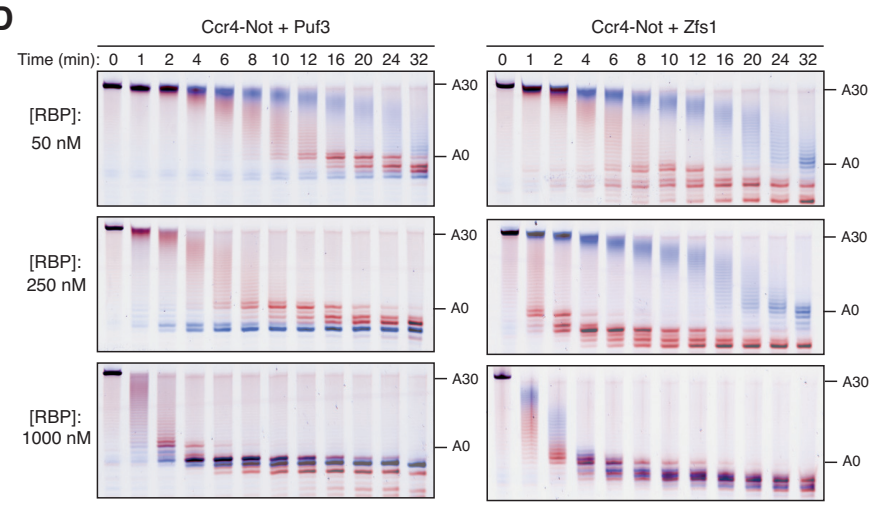

Figure 3. Puf3 and Zfs1 mediate selective deadenylation by Ccr4-Not

(A) Puf3 and Zfs1 accelerate deadenylation of RNAs with or without a target recognition motif. Puf3 or Zfs1 was added to PRE-containing RNA (Puf3-target) or ARE-containing RNA (Zfs1-target) before addition of Ccr4-Not. Deadenylation was analyzed by denaturing PAGE. Top right and bottom right panels are reproduced from Figure 1B. (B) Fluorescence polarization experiments assaying the binding of fulllength Puf3 (top) or Zfs1 (bottom) to 5'-6FAM labelled RNAs. Error bars represent the standard error in triplicate measurements. (C) Deadenylation of a mixture of 100 nM fluorescein-labelled Puf3-target RNA (blue) and $100 \mathrm{nM}$ Alexa647-labelled Zfs1target RNA (red) analyzed by denaturing PAGE. Gels were scanned to detect each fluorophore before signals were overlaid. (D) Puf3 and Zfs1 promote selective deadenylation. Reactions were performed as in (C) but with the addition of Puf3 (left) or Zfs1 (right) at the indicated concentrations. 
A

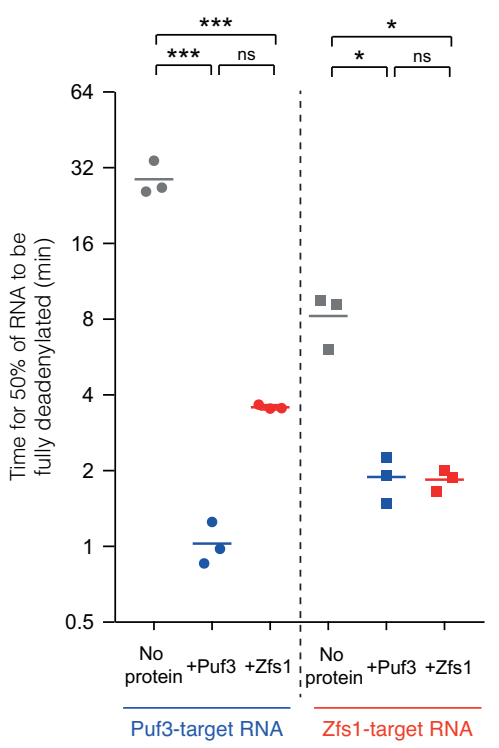

B

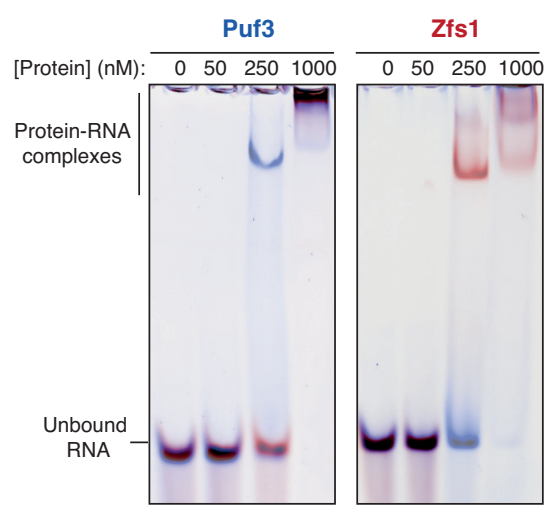

Figure 3-figure supplement 1. Analysis of RNA selectivity during deadenylation

(A) Quantification of on-target and off-target deadenylation rates. Densitometric analysis of the amount of fully deadenylated RNA was performed on gels shown in Figure 3A. Each experiment is presented as a single data point, and the mean of triplicate experiments is plotted as a horizontal line. Time for complete deadenylation, rather than change in modal poly(A) tail length, was calculated because these reactions contained low levels of intermediates between non-deadenylated and fullydeadenylated RNA. ns, not significant; *, p=0.05; ***, p=0.001. (B) Electrophoretic mobility shift assays showing selective RNA binding of Puf3 and Zfs 1 . A mixture of $100 \mathrm{nM}$ fluorescein-labelled Puf3-target-A30 RNA (red) and $100 \mathrm{nM}$ Alexa647labelled Zfs1-target-A30 RNA (blue) was incubated with the indicated concentration of Puf3 or Zfs1. Gels were scanned with a Typhoon FLA-7000 with excitation at 478 $\mathrm{nm}$ (fluorescein detection) and $633 \mathrm{~nm}$ (Alexa647 detection), and images were superimposed with color overlay. 
A

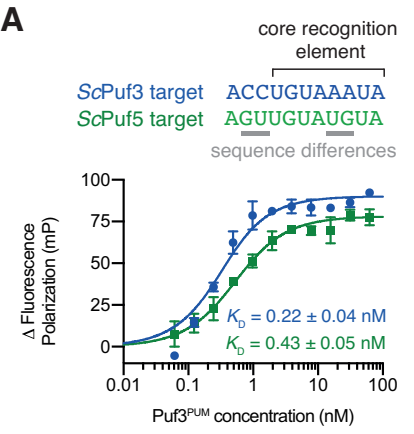

C

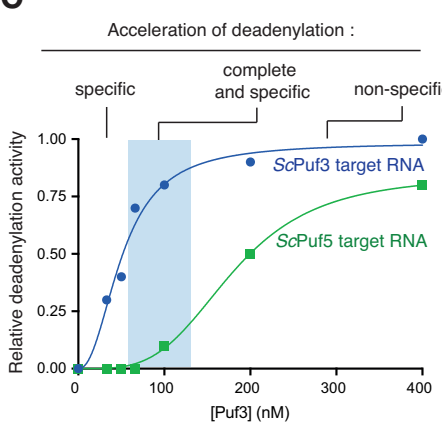

B

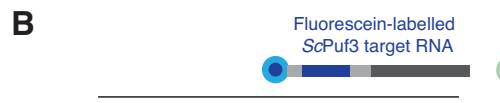

Alexa647-labelled ScPuf5 target RNA

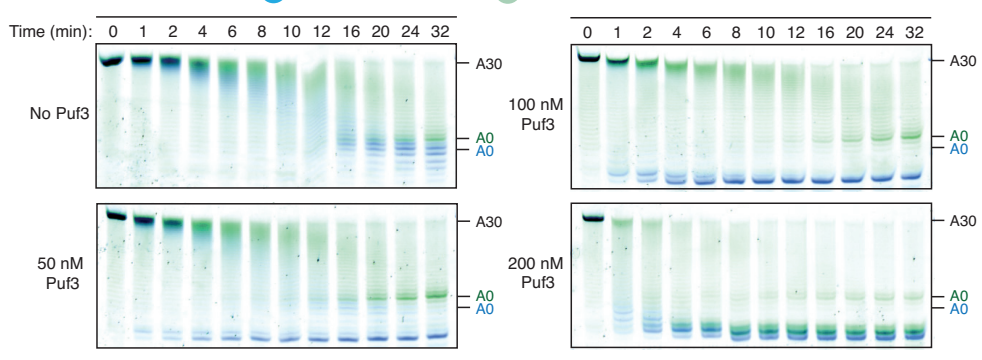

D

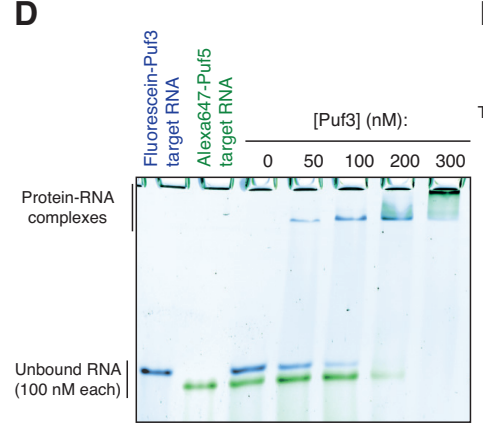

E $\quad$ SCPuf3 target (5A) ACCUGUAAAUA

SCPuf3 target (5U) ACCUGUAUGUA sequence difference

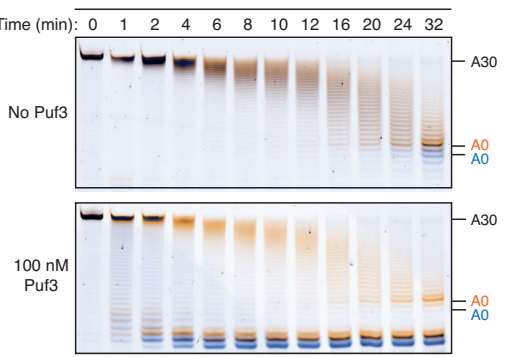

Figure 4. Puf3 distinguishes between similar RNA motifs

(A) Fluorescence polarization experiments assaying the binding of Puf3 RNA-binding domain to RNA containing a $S c$ Puf3 motif (blue) or a $S c$ Puf5 motif (green). Error bars represent the standard error in triplicate measurements. (B) Deadenylation of a mixture of fluorescein-labelled ScPuf3-target RNA (blue) and Cy3-labelled ScPuf5target RNA (green) analyzed by denaturing PAGE. Gels were scanned to detect each fluorophore before signals were overlaid. (C) Selective deadenylation occurs within a narrow range of Puf3 concentrations. Plot of relative deadenylation rates of $S c$ Puf3target RNA and ScPuf5-target RNA in reactions as in (B) at a series of Puf3 concentrations. Reactions were quantified based on the fraction of RNA fully deadenylated within 8 minutes. (D) Electrophoretic mobility shift assay showing the binding of Puf3 to a mixture of fluorescein-labelled ScPuf3-target RNA (blue) and Cy3-labelled ScPuf5-target RNA (green). The concentration of each RNA was 100 nM. (E) Deadenylation of a mixture of fluorescein-labelled $S c$ Puf3(5A)-target RNA (blue) and Alexa647-labelled ScPuf3(5U)-target RNA (orange) analyzed by denaturing PAGE. Gels were scanned to detect each fluorophore before signals were overlaid. 


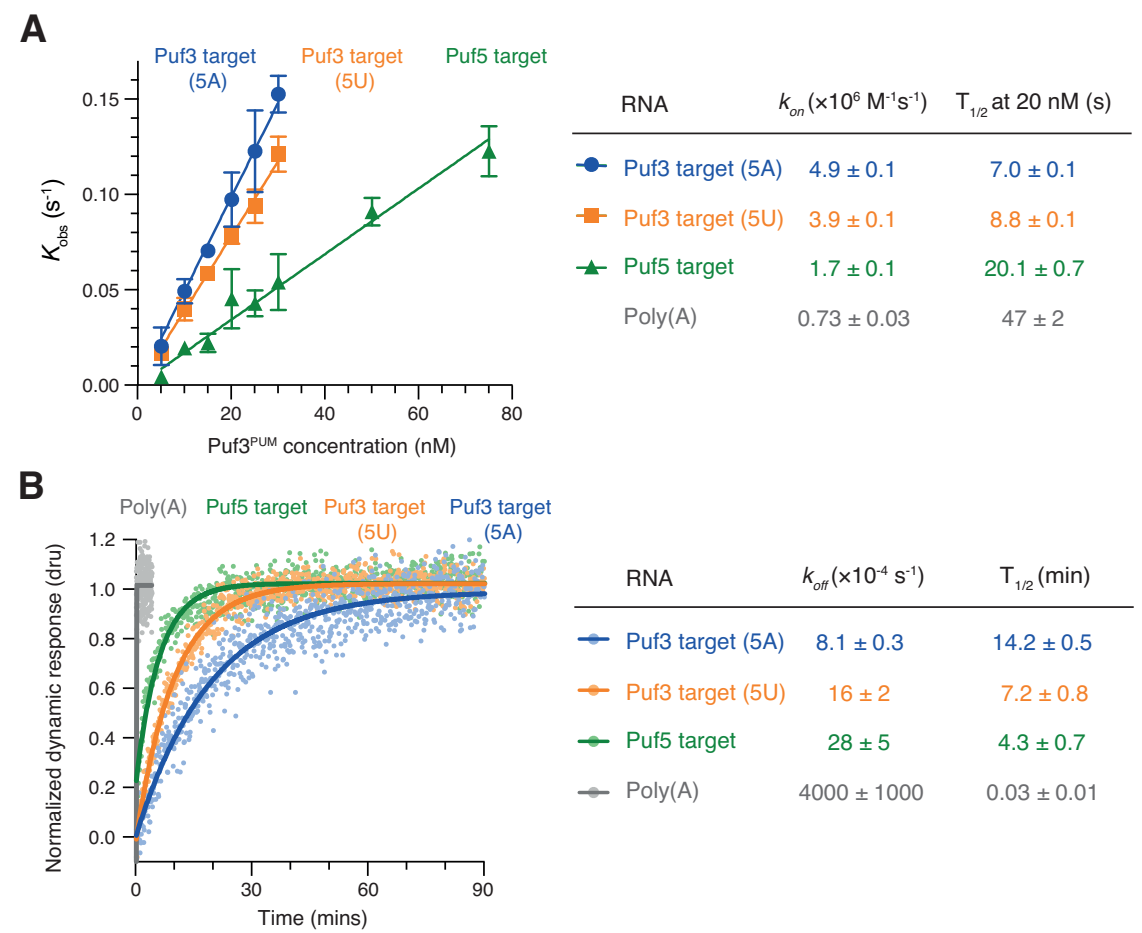

Figure 5. RNA motif quality affects Puf3 binding kinetics

(A) The kinetic rates of association $\left(k_{o n}\right)$ of purified Puf3 ${ }^{\text {PUM }}$ with RNA containing the indicated $S$. cerevisiae sequence motifs were determined by SwitchSENSE. Error bars are the standard error. (B) Representative SwitchSENSE sensograms showing the dissociation of $\mathrm{Puf}^{\mathrm{PUM}}$ from the indicated $S$. cerevisiae RNA sequences. dru, dynamic response units. In (A) and (B), rate constants and half-lives are shown with standard error for measurements performed in triplicate. 
A

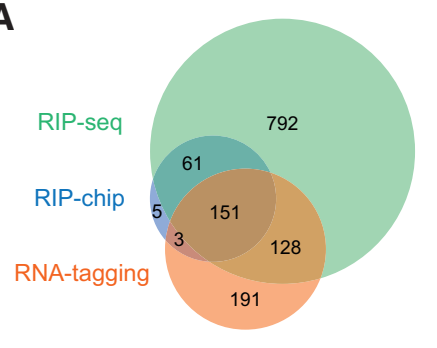

D
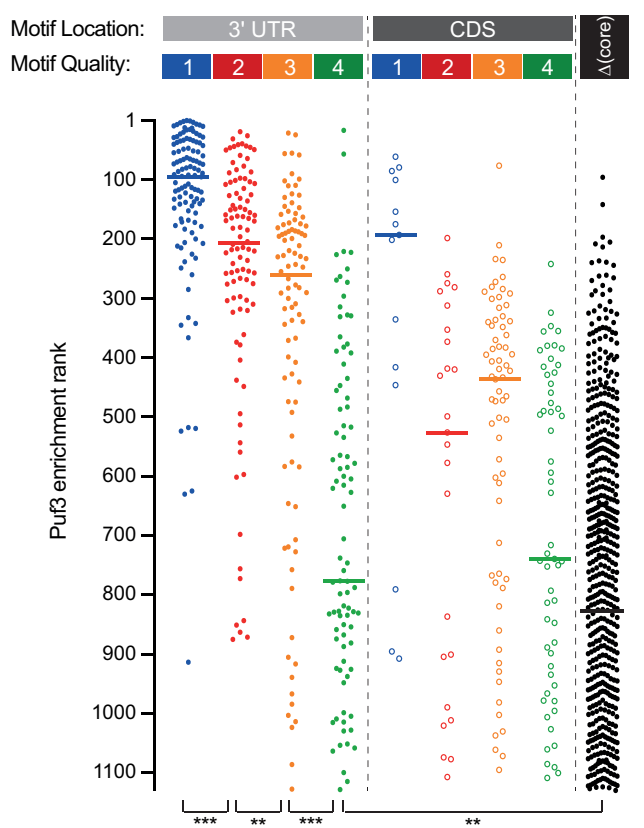

B

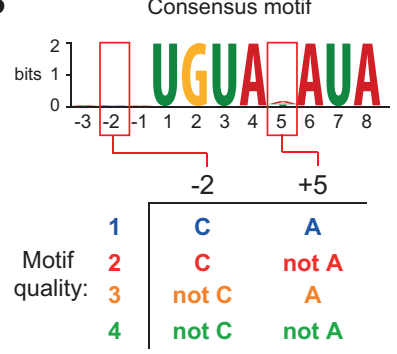

C mRNAs increased in steady-state abundance in puf3 $\Delta$ cells

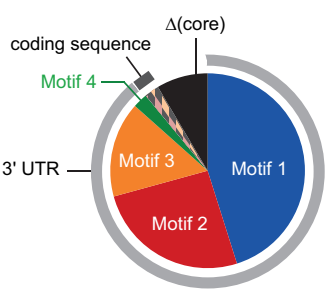

E

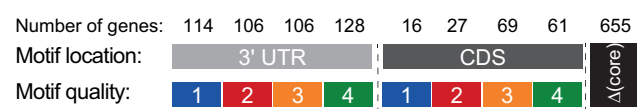
Motif quality:

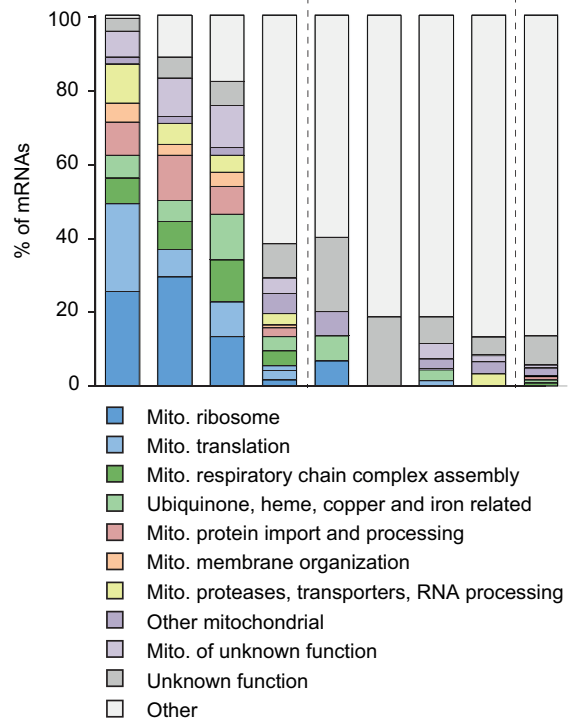

Figure 6. RNA motif quality defines a coherent mRNA regulatory network

(A) Overlap between the putative mRNAs bound by $S$. cerevisiae Puf3 determined by RIP-seq (Kershaw et al., 2015), RIP-chip (Gerber et al., 2004) and RNA-tagging (Lapointe et al., 2015). The numbers of mRNAs identified in each study is given. (B) Consensus motif identified from the complete set of putative $S c$ Puf3 mRNA targets. Definition of categories of Puf3 motif quality is shown below. (C) Diagram showing RNA motif quality and location in mRNAs that increase in abundance upon PUF3 deletion (Kershaw et al., 2015). (D) ScPuf3 binding versus RNA motif quality and location. Median enrichment rank is indicated with horizontal line. Statistical significance was evaluated with a Mann-Whitney rank comparison test. ${ }^{* *}, \mathrm{p}=0.01$; ***, $\mathrm{p}=0.001$. (E) mRNAs with high quality ScPuf3-target motifs encode proteins related to mitochondrial biogenesis. 
A

A

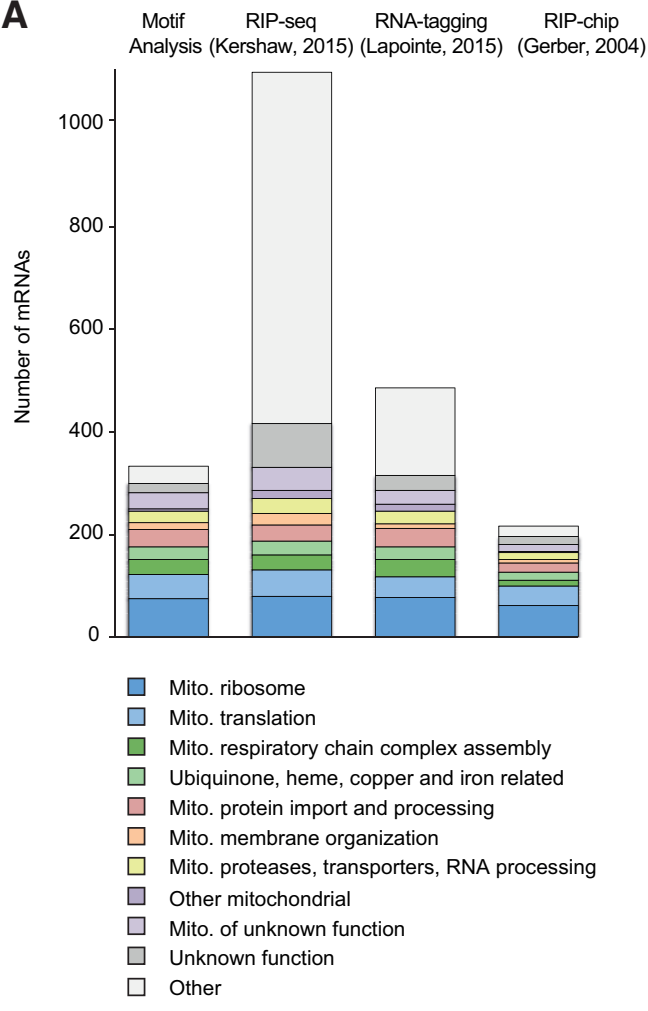

C

Motif 4 (mitochondrial biogenesis related)

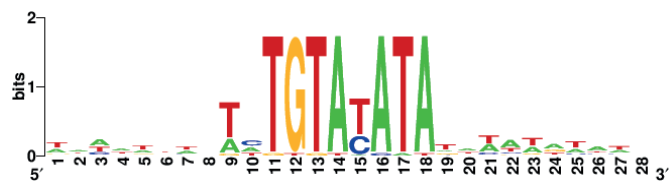

Motif 4 (not mitochondrial biogenesis related)

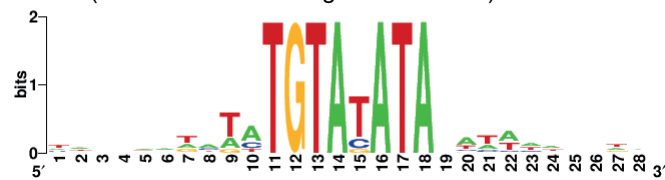

B

Motif Quality:
Related to

mitochondrial

biogenesis?

\section{$1,2,3$}

4

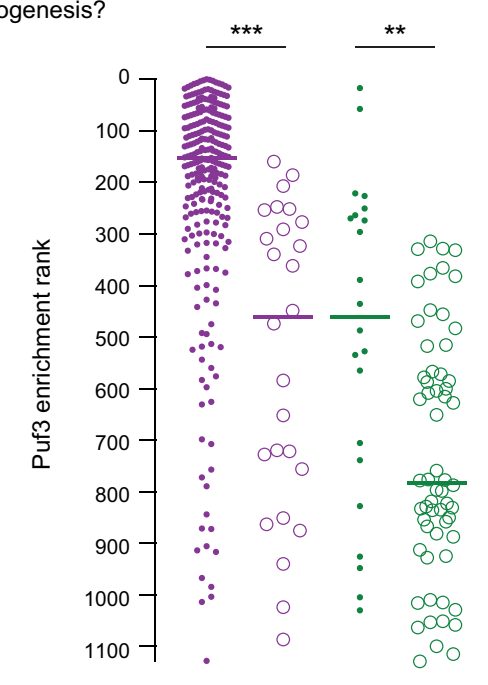

Figure 6-figure supplement 1. Evaluation of mRNA target prediction by motif quality analysis

(A) Comparison of the encoded functions of mRNAs identified as targets of ScPuf3 by different methods. (B) Within a single motif category, mRNAs encoding proteins related to mitochondrial biogenesis are more enriched in ScPuf3 binding. Statistical significance was evaluated with a Mann-Whitney rank comparison test in GraphPad Prism. **, $\mathrm{p}=0.01 ; * * *, \mathrm{p}=0.001$. (C) Comparison of RNA sequence context of motifs in category 4 between mRNAs that encode mitochondrial biogenesis proteins and those that do not. 
A

A
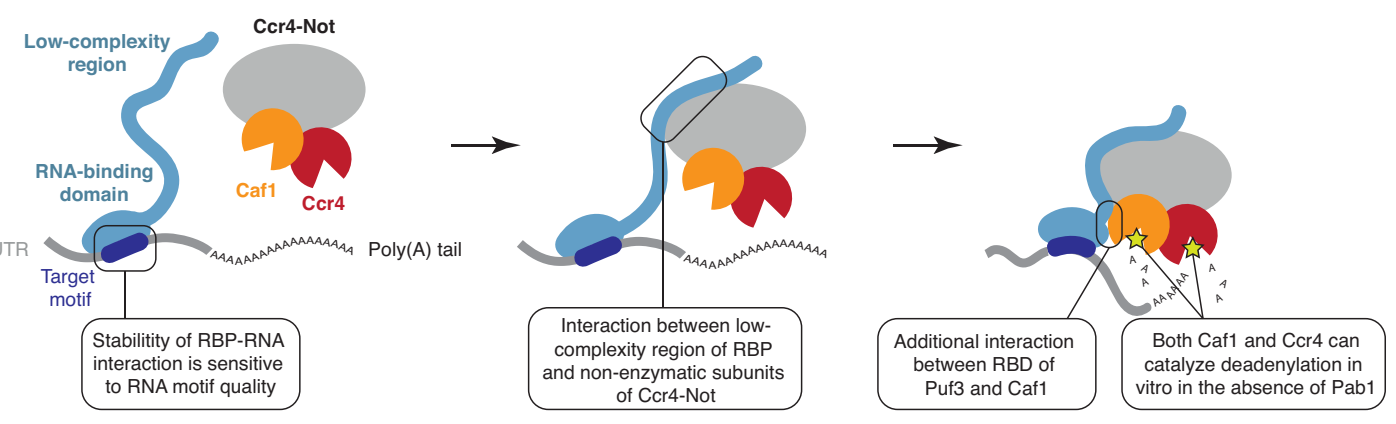

B

Puf3-target RNA Non-target RNA

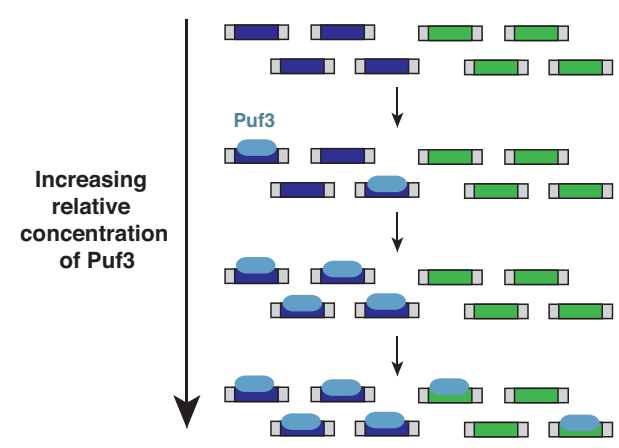

C

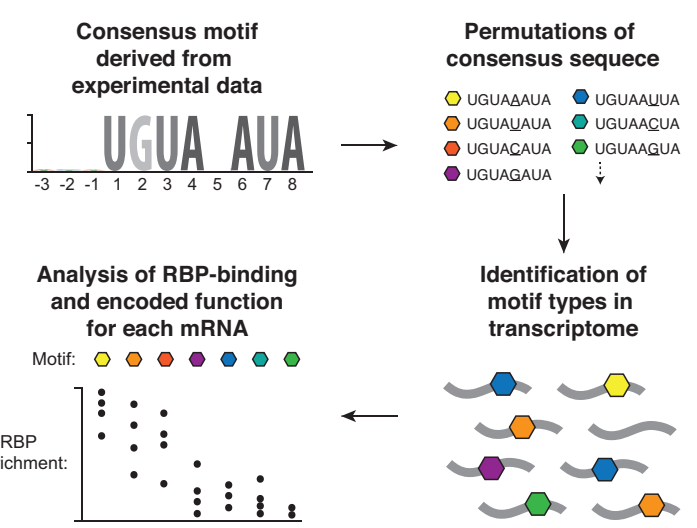

Figure 7. Models for substrate selectivity in deadenylation

(A) RNA-binding proteins (RBPs) promote targeted deadenylation by simultaneously binding to RNA via an RNA-binding domain (RBD) and to Ccr4-Not via a lowcomplexity region. These interactions can be regulated by post-translational modifications. (B) Model for priority-based binding of Puf3 to RNA. (C) Scheme for defining target sequences of RNA-binding proteins. 


\section{Supplementary File 1: Analysis of Puf3-motif quality in putative mRNA targets of Puf3}

This table includes the $S$. cerevisiae mRNAs that are candidates for Puf3 regulation, obtained from published sources as detailed in Methods. The highest quality motif present in each mRNA is indicated with the category numbers defined in Figure 6B (1-4), and 5 for $\Delta$ core. Functional categories were defined in this study based on published data obtained from the SGD database.

\section{Supplementary File 2: Gene Ontology analysis of mRNA groups defined by Puf3-motif quality and location}

Statistically significant gene ontology over-representation was identified with PANTHER as detailed in Methods. Terms were identified for the mRNA groups defined by the presence of motifs 1, 2 or 3 within the 3' UTR (see Figutre 6B for motif quality definitions). No significantly enriched GO terms were identified for motif 4 in the 3' UTR or for any groups with motifs in the coding sequence.

Significantly enriched GO terms for the mRNAs defined by a mismatch within the 7 core nucleotides ( $\Delta$ core) were identified and are shown here.

\section{Supplementary File 3: Plasmids and Oligonucleotides}

Plasmids and oligos used in this study are listed. 
Table 1: Sequences of RNAs used in this study

\begin{tabular}{lll}
\hline Name & Sequence & Experiment \\
\hline Zfs1 target A30 & AAUCAUCCUUAUUUAUUACCAUU[A]30 & Deadenylation \\
Puf3 target A30 / & AACUGUUCCUGUAAAUACGCCAG[A]30 & Deadenylation \\
Puf3 target (5A) A30 & AACUGUUCCUGUAUAUACGCCAG[A]30 & Deadenylation \\
Puf3 target (5U) A30 & AACUGUUGUUGUAUGUACGCCAG[A]30 & Deadenylation \\
Puf5 target & AUUAUUUAUU & $\begin{array}{l}\text { Fluorescence } \\
\text { polarization }\end{array}$ \\
ARE / Zfs1 target & ACCUGUAAAUA & $\begin{array}{l}\text { Fluorescence } \\
\text { polarization }\end{array}$ \\
PRE / Puf3 target (5A) & ACCUGUAUAUA & $\begin{array}{l}\text { Fluorescence } \\
\text { polarization }\end{array}$ \\
Puf3 target (5U) & AGUUGUAUGUA & $\begin{array}{l}\text { Fluorescence } \\
\text { polarization }\end{array}$ \\
Puf5 target & & $\begin{array}{l}\text { Fluorescence } \\
\text { polarization }\end{array}$ \\
A30 & [A]30 & SwitchSENSE \\
Puf3 target (5A) & ACCUGUAAAUAGGCG-[*DNA] & SwitchSENSE \\
Puf3 target (5U) & ACCUGUAUAUAGGCG-[*DNA] & SwitchSENSE \\
Puf5 target & AGUUGUAUGUAGGCG- $*$ DNA] & SwitchSENSE \\
Poly(A) & {$[$ A]15-[*DNA] } &
\end{tabular}

*DNA for hybridization to nanolever:

ATCAGCGTTCGATGCTTCCGACTAATCAGCCATATCAGCTTACGACTA 